Universidad de Lima

Facultad de Psicología

Carrera de Psicología

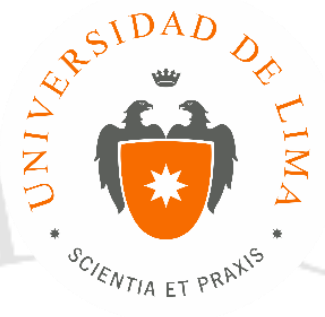

\title{
DEPENDENCIA EMOCIONAL Y AUTOESTIMA GENERAL Y CONTINGENTE A LAS RELACIONES DE PAREJA EN MUJERES ADULTAS EN UNA RELACIÓN DE PAREJA DE LIMA METROPOLITANA
}

Tesis para optar el título profesional de Licenciado en Psicóloga

\section{Giulia Camaiora Chiappe}

20110222

\author{
Asesor \\ Andrés Burga León
}

Lima - Perú

Diciembre de 2018 


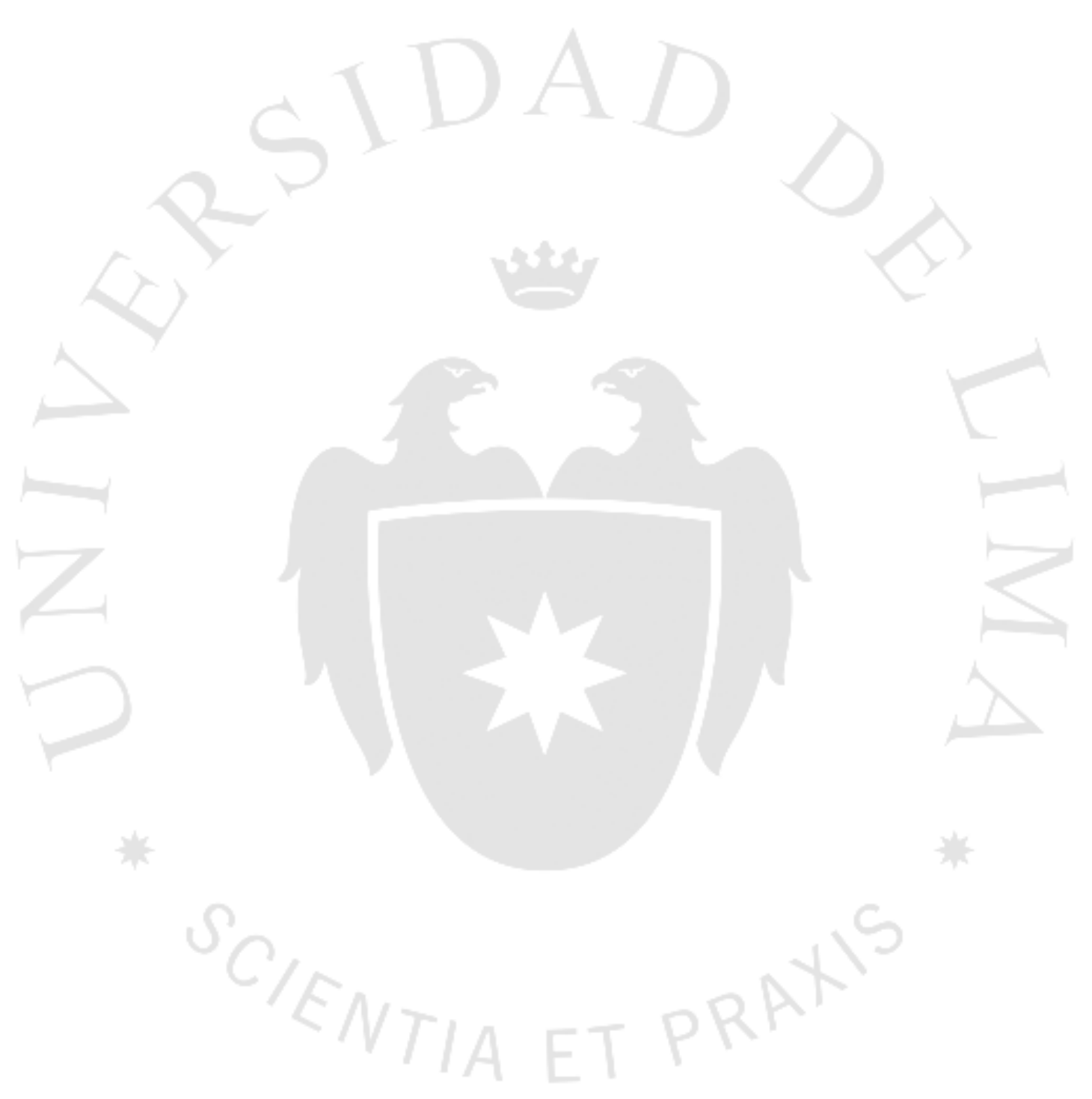




\section{DEPENDENCIA EMOCIONAL Y AUTOESTIMA GENERAL Y CONTINGENTE A LAS RELACIONES DE PAREJA EN MUJERES ADULTAS EN UNA RELACIÓN DE PAREJA DE LIMA METROPOLITANA}




\section{RESUMEN}

El presente estudio tiene como objetivo describir la relación entre la dependencia emocional y la autoestima general y contingente a las relaciones de pareja para mujeres entre 18 a 45 años en Lima Metropolitana; así como analizar las propiedades psicométricas de dos pruebas: Escala de Autoestima de Rosenberg y de la Escala de Autoestima Contingente a las Relaciones de Pareja. Se evaluó a 163 mujeres con el Inventario de Dependencia Emocional y los dos instrumentos mencionados previamente. Los resultados evidenciaron correlaciones estadísticamente significativas entre las variables. Se obtuvo una relación negativa entre la dependencia emocional y la autoestima general y una relación positiva entre la dependencia emocional y la autoestima contingente a las relaciones de pareja. Asimismo, para la Escala de Autoestima de Rosenberg y la Escala de Autoestima Contingente a las Relaciones de Pareja, se obtuvo la unidimensionalidad y las evidencias de confiabilidad de .90 y .88 respectivamente.

Palabras clave: dependencia emocional, autoestima general, autoestima contingente a las relaciones de pareja, mujeres en una relación de pareja, propiedades psicométricas.

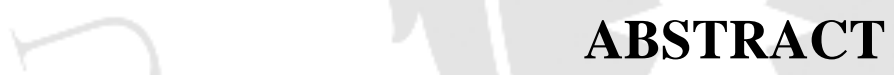

The present study had the objective to describe the relationship between emotional dependency and general and relationship contingent self-esteem in women from 18 to 45 years of Lima Metropolitana; as well as analyze the psychometric properties of two tests: Rosenberg Scale and the Relationship Contingent Self Esteem. A total of 163 women were evaluated with the Inventory of Emotional Dependency and the other two tests mentioned previously. The findings revealed that there was evidence of significant statistical correlation between the variables: a negative relation between emotional dependency and self-esteem, and a positive relation between emotional dependency and relationship contingent self-esteem. Likewise, they provided the unidimensionality of the Rosenberg Scale and the Relationship Contingent Self Esteem and the evidence of reliability .90 and .88 respectively.

Key words: emotional dependency, self-esteem, Relationship Contingent Self Esteem, women in a relationship, Lima. 


\section{TABLA DE CONTENIDO}

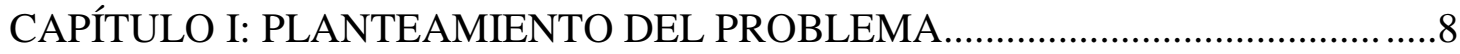

1.1 Descripción del problema........................................8

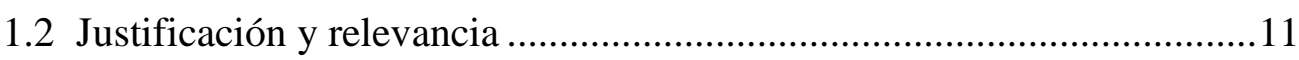

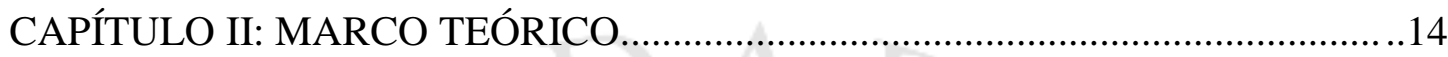

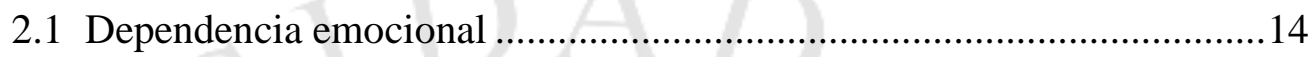

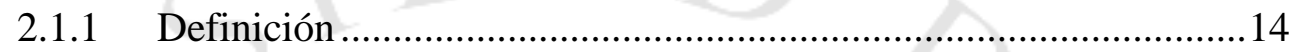

2.1.2 Características de la dependencia emocional ................................15

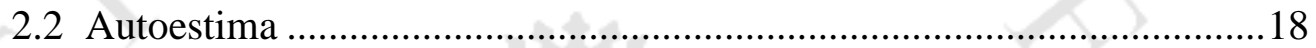

2.2.1 Definición de la autoestima general ............................................. 18

2.2.2 Niveles de autoestima general ..................................................19

2.2.3 Formación de la autoestima general en la vida de las personas .....21

2.2.4 Autoestima Contingente ….......................................................22

2.3 Relación entre dependencia emocional y autoestima............................23

CAPÍTULO III: OBJETIVOS, HIPÓTESIS Y DEFINICIÓN DE VARIABLES ....26

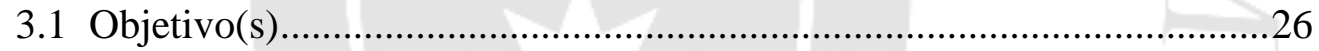

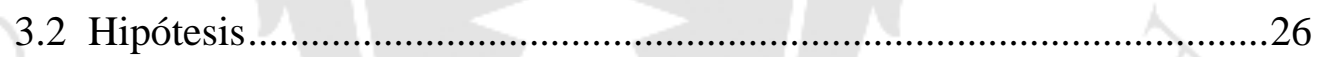

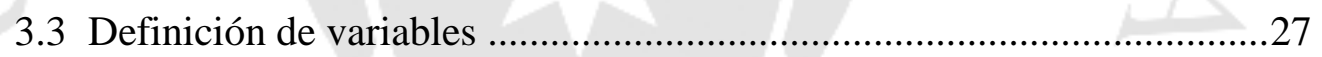

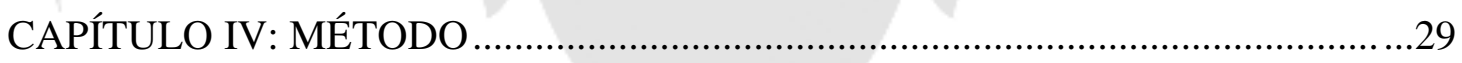

4.1 Tipo y diseño de investigación..............................................................29

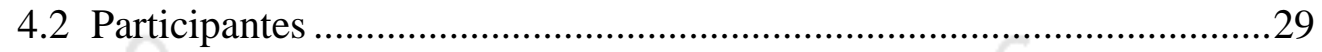

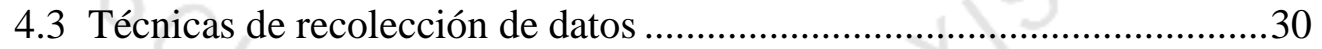

4.4 Procedimiento de recolección de datos ...................................................31

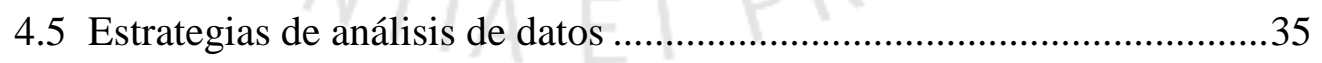

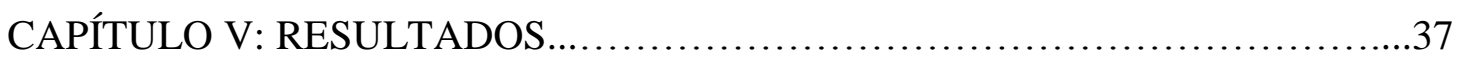

CAPÍTULO VI: DISCUSIÓN ..........................................52

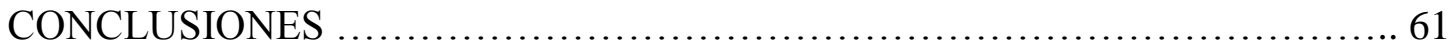

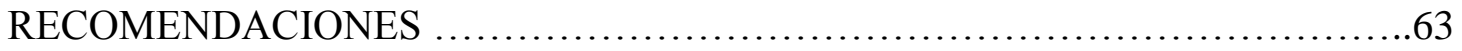

REFERENCIAS ......................................................64

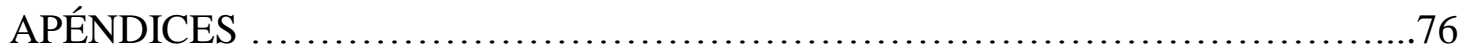




\section{ÍNDICE DE TABLAS}

Tabla 4.1 Características de la muestra

Tabla 4.2 Alfa de Cronbach de los factores del Inventario de dependencia emocional

Tabla 5.1 Coeficiente V de Aiken para los ítems de la Escala de Autoestima

Contingente a las Relaciones de Pareja.....

Tabla 5.2 Cargar factoriales de losítems que conforman la escala de Autoestima

Contingente a las Relaciones de Pareja a dos factores

Tabla 5.3 Cargas factoriales de los ítems de la estructura final de la Escala de Autoestima Contingente a las Relaciones de Pareja....

Tabla 5.4 Correlación ítem - test corregida y alfa de Cronbach si el ítem es eliminado42

Tabla 5.5 Coeficiente V de Aiken para los ítems de la Escala de Autoestima General. 43

Tabla 5.6 Cargas factoriales de los ítems de la estructura final de la prueba de Autoestima de Rosenberg 44

Tabla 5.7 Correlación ítem - test corregida y alfa de Cronbach si el ítem es eliminado45

Tabla 5.8 Correlación ítem - test corregida y alfa de Cronbach si el ítem es eliminado 46

Tabla 5.9 Estadísticos descriptivos y pruebas de normalidad de las puntuaciones de los cuestionarios para la muestra total $(\mathrm{N}=163)$

Tabla 5.10 Coeficiente de Correlación Rho Spearman para las relaciones significativas de cada una de las escalas

Tabla 5.11 Coeficiente de Correlación Rho Spearman por factores de la Escala de Dependencia Emocional.

Tabla 5.12 Estadísticos descriptivos y normalidad de la variable violencia y los puntajes de las pruebas 


\section{ÍNDICE DE APÉNDICES}

Apéndice 1: Ficha Sociodemográfica

Apéndice 2: Cuestionario de Autoestima de Rosenberg versión de Rojas-Barahona et al. (2009)

Apéndice 3: Escala de Autoestima Contingente a las Relaciones de Pareja adaptado por

el presente estudio .79

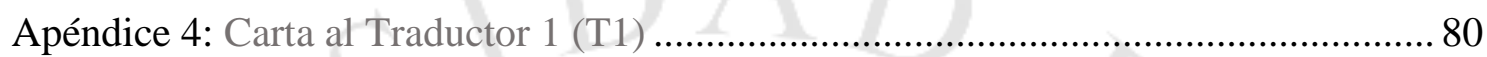

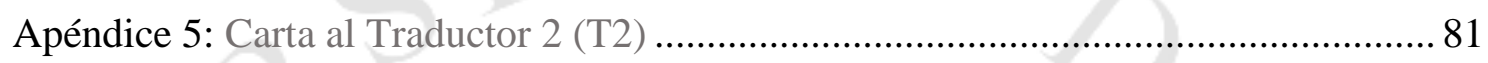

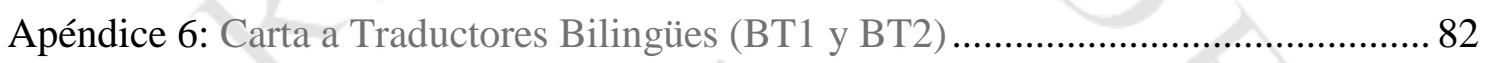

Apéndice 7: Carta para el Comité Multidisciplinario de Expertos................................. 83

Apéndice 8: Formato de prueba a evaluar para el Comité Multidisciplinario de

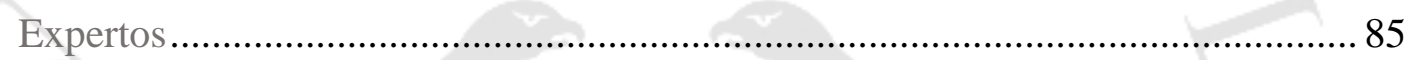

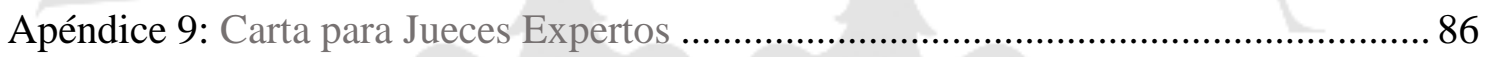

Apéndice 10: Formato de prueba a evaluar para Jueces Expertos ................................ 87

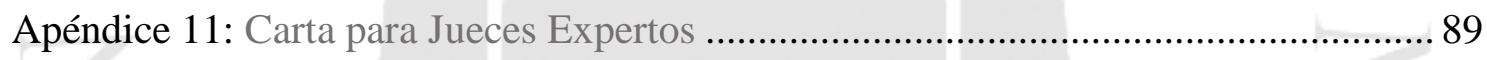

Apéndice 12: P Formato de prueba a evaluar para Jueces Expertos ............................. 90

Apéndice 13: Permiso del Inventario de Dependencia Emocional - IDE ....................... 91

Apéndice 14: Permiso de la Escala de Autoestima de Rosenberg ............................... 92

Apéndice 15: Permiso de Relationship Contingent Self -Esteem Scale ........................93

Apéndice 16: Consentimiento Informado ................................................................... 94

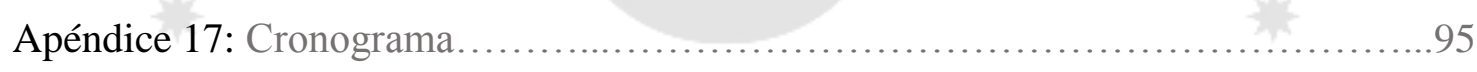

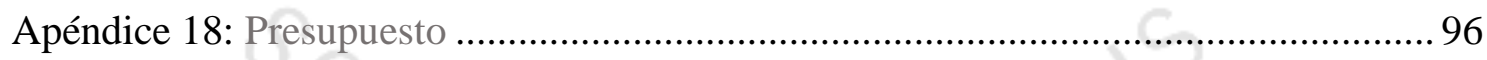




\section{CAPÍTULO I: PLANTEAMIENTO DEL PROBLEMA}

\subsection{Descripción del problema}

El individuo, según la teoría de la autodeterminación, tiene tres necesidades psicológicas básicas: competencia, autonomía y relación (Deci y Ryan, 2000). Esta última consiste en que la persona se encuentre en una constante interacción con el entorno, sea sociable y se sienta integrada y comprendida por los demás, permitiéndole desarrollarse como ser humano y adaptarse a la sociedad (Deci y Ryan, 2000; Fromm, 1978). Esta necesidad se inicia como un acto de cariño, entrega y generosidad hacia el otro, dejando de lado ciertos intereses personales y habilidades sociales, donde el amor propio y el respeto permiten tener una relación saludable (Capafóns y Sosa, 2015; Knee, Bush, Canevello y Cook, 2008; Riso, 2012a).

Cuando el apego es excesivo forma parte de esta necesidad, la relación pasa a ser intensa con la pareja, el individuo pierde el autorespeto y comienza la despersonalización, convirtiendo a la dependencia emocional en la base y la razón de la relación, siendo dañino para uno de los miembros (Aiquipa, 2012; Riso, 2012a). La dependencia emocional es un término reciente utilizado por la psicología, derivado del trastorno de personalidad dependiente y va de la mano con el sentimiento de soledad, la falta de autonomía, la necesidad del otro, un autoconcepto bajo y con la ansiedad de separación (APA, 2014; Castelló 2000, 2005; Lemos y Londoño, 2006).

Con respecto a la revisión de investigaciones acerca de la dependencia emocional y sus consecuencias, se puede evidenciar en un estudio con una población española, realizado por Echeburúa, Amor y De Corral (2002), que el estrés post traumático es un resultado de que la mujer se mantenga en una relación de pareja en la que es víctima de violencia o maltrato (física, psicológica y/o sexual). Se debe a que esta cuenta con 
características de una baja autoestima, sentimientos de culpa y poca asertividad, la cual la llevan a ser dependiente emocional de su pareja y se mantiene dentro de la relación por evitar una ruptura y teme encontrarse sola en un futuro.

Asimismo, en el contexto peruano se encontró una investigación realizada por Fiestas y Piazza (2014) en la que se determinó que en una población de 3930 sujetos, donde más de la mitad (52\%) eran mujeres, 15\% de ellas -comprendidas entre los 18 y 45 años,- presentaron un trastorno de ansiedad de separación caracterizado por sentir un temor intenso a distanciarse de alguien con quien tuvo un vínculo muy estrecho, manifestando malestar psicológico, rechazo a estar solo y/o síntomas físicos (Tortella-Feliu, 2014). Estas sintomatologías son similares a las de una persona dependiente emocional de su pareja (Castelló 2000, 2005). Además en otro estudio realizado en la ciudad de Lima (Huerta et al., 2016), confirmó que los esquemas disfuncionales formados a temprana edad incrementan la dependencia emocional en las mujeres. Ponen en riesgo la salud mental, provocando ansiedad, depresión, baja autoestima y entre otros trastornos psicosomáticos.

Las personas dependientes emocionalmente suelen minimizar los aspectos positivos de sí mismos y mantener un exceso de sentimientos negativos relacionados a su entorno, donde la autoestima es la gran responsable de estas características (Castelló, 2005). Por este motivo, en la presente investigación se verá la relación de la dependencia emocional con la autoestima desde el aspecto general y el contingente a las relaciones de pareja.

En relación a la autoestima general, se define como la valoración que tiene el individuo sobre sí mismo, esta puede ser positiva o negativa (Rosenberg, 1979). Cuando es baja, el individuo tiene una mayor predisposición a depender de su pareja (Castelló, 2005). Una de las causas es el poco afecto, amor y valoración por parte de sus seres significativos, lo cual lo lleva a presentar una carencia de estrategias de afrontamiento que lo ayude a encontrarse y sentirse bien al estar sin la pareja, mostrando 
lo contrario (Castelló, 2000, 2005; Mayor, 2000). Suelen tener una mayor sumisión dentro de la relación e idealizan al otro (Murray, Holmes y Griffin, 2000; Luciano y Orth, 2016).

Con respecto a la autoestima contingente a la relación de pareja, la valoración que tiene el individuo sobre sí mismo está sujeta a cómo se encuentre con su pareja (Knee et al., 2008). Las personas suelen ver significativos los eventos que ocurren dentro de su relación y se aferran más al otro por el miedo que les produce el estar solos, buscando satisfacer a la pareja y volviéndose cada vez más dependientes (Knee et al., 2008).

A partir de los estudios mencionados previamente, se busca encontrar la relación entre la dependencia emocional y la autoestima, considerándose relevante y como un aporte para la sociedad peruana debido a las tasas de violencia en las parejas, las consecuencias negativas que trae el mantenerse en una relación no saludable y la falta de investigaciones previas en nuestro contexto. Por lo tanto, se plantean los siguientes problemas de investigación: ¿Existe una relación entre la dependencia emocional y la autoestima general en mujeres adultas en una relación de pareja de Lima Metropolitana? ¿Existe una relación entre la dependencia emocional y la autoestima contingente a las relaciones de pareja en mujeres adultas en una relación de pareja de Lima Metropolitana?

Con la finalidad de poder conocer la relación entre ambas variables, es necesario utilizar instrumentos cuantitativos y adaptados en el contexto a aplicar. En primer lugar, se utilizará el Inventario de Dependencia Emocional (IDE) elaborado y validado por Aiquipa (2012) en el Perú. Dicho instrumento tiene un fundamento teórico sustentado en el modelo planteado por Heathers (1955), en la teoría de los rasgos de personalidad (Cloninger, 2003) y el modelo afectivo de Castelló (2005). Respecto al segundo instrumento a utilizar, será la Escala de Autoestima de Rosenberg (1965), versión adaptada en Chile (Rojas-Barahona, Zegers y Förster, 2009). Por último, se utilizará la Escala de Autoestima Contingente a las 
Relaciones de Pareja (Knee et al., 2008), creada y validada en Houston, Estados Unidos.

Debido a que las pruebas mencionadas previamente no están estandarizadas, el estudio presenta algunas interrogantes secundarias a las cuales debe responder:

¿Cuáles son las evidencias de validez vinculadas al contenido y a la estructura interna de la Escala de Autoestima de Rosenberg y de la Escala de Autoestima Contingente a las Relaciones de Pareja?

¿Cuáles son las evidencias de confiabilidad de las puntuaciones derivadas de aplicar la Escala de Autoestima de Rosenberg y la Escala de Autoestima Contingente a las Relaciones de Pareja?

\section{Justificación y relevancia}

La importancia del presente estudio radica en que la dependencia emocional y la autoestima son factores que están presentes en la vida y en las relaciones de pareja de todas las personas (Castelló, 2000, 2005). Esto genera la necesidad de incrementar el conocimiento que se tiene acerca de cada una de las variables y de la relación entre ambas. Es por eso que el principal aporte es teórico, porque se basa en incrementar el cuerpo de conocimiento sobre la dependencia emocional en una población peruana e investigar sobre su relación con la variable autoestima: general y contingente a las relaciones de pareja.

Al revisar bases de datos como APA PsycNET, Dialnet, E-Libro, Ebsco, Proquest, Psicodoc y revistas académicas de la Pontificia Universidad Católica del/Perú, la Universidad Nacional Mayor de San Marcos, Universidad San Martín de Porres, Universidad Ricardo Palma, y Universidad de Lima, se ingresaron términos como dependencia emocional y autoestima, dependencia emocional y autoestima contingente en parejas, etc., se encontró escasa información e insuficiente evidencia empírica sobre las variables a estudiar.

Por otro lado, los datos brindados en la investigación servirán como aporte para los procesos de intervención terapéutica por lo que conlleva a una 
contribución práctica al brindar datos e información que contribuyan a la mejora de los programas terapéuticos que se utilizan en la actualidad dentro de nuestro contexto. Como sería en el caso de la autoestima que cuenta con algunas propuestas de intervención psicológica efectivas como la autoevaluación precisa (Mckay y Fanning, 1991), psicoterapia breve centrada en solución de problemas (Eskin, Ertekin y Demir, 2008; Nezu, Nezu y D’Zurilla, 2014), reestructuración cognitiva (Clark y Beck, 2012; Ortega Otero, Kendzierski y Aranda Rubio, 2015), entre otras.

Con respecto a la población evaluada, se eligió a mujeres en una relación de pareja, porque tienen un mayor tendencia a requerir afecto y un mayor miedo a la soledad en comparación con los hombres (Lemos y Londoño, 2006). Lo mencionado previamente se puede evidenciar en nuestro país. El Ministerio de la Mujer y Poblaciones Vulnerables (2017), realizó una estadística donde 73163 mujeres sufren maltrato principalmente por parte de la pareja o esposo y continúan dentro de la relación. Las consecuencias que trae el mantenerse dentro de una relación de pareja están relacionadas a trastornos o problemas de salud mental que se evidencian a futuro como: la autoestima baja, depresión, estrés postraumático, trastorno de ansiedad de separación o abuso de sustancias, tanto en las mujeres violentadas como en sus hijos o familiares cercanos, afectando la calidad de vida y el desarrollo adecuado de una familia y de la sociedad en la que se vive (Boeckel, Blasco-Ros, Grassi-Oliveira, y Martínez, 2014; Caballero, Alfaro, Nuñez y Torres, 2009; Román, 2011; Vargas, 2017).

A su vez, existen pocos instrumentos adaptados a nuestro contexto que ayuden a su medición, limitando la extensión y profundidad de conocimiento que se tiene acerca de estas variables. Debido a esto, el estudio brindará un aporte metodológico, ya que se adaptarán la Escala de Autoestima de Rosenberg (Rojas-Barahona et al., 2009) y la Escala de Autoestima Contingente a las Relaciones de Pareja (Knee et al., 2008) al uso lingüístico de Lima Metropolitana. Asimismo, se dará un aporte psicométrico, ya que se recopilarán las evidencias de validez y confiabilidad de los puntajes obtenidos y los resultados serán útiles para 
replicar las pruebas en futuras investigaciones en contextos y poblaciones similares.

El estudio surge a partir de lo mencionado previamente; la carencia de fuentes teóricas comprobadas, la falta de investigaciones previas e instrumentos adaptados, la violencia dentro de las relaciones de pareja y las consecuencias que trae el mantenerse en una relación no saludable como los trastornos mentales en nuestro país. Debido a esto, se desea analizar y comparar la relación de la dependencia emocional en mujeres, con la autoestima general y la autoestima contingente a las relaciones de pareja de Lima Metropolitana. 


\section{CAPÍTULO II: MARCO TEÓRICO}

\subsection{Dependencia emocional}

\subsubsection{Definición}

La dependencia emocional es la necesidad dominante y excesiva que tiene un individuo para que lo cuiden, la cual lleva a un comportamiento dócil y de apego exagerado, generando miedo a la separación (American Psychiatric Association, 2014). Es un trastorno de relación caracterizado por la manifestación de comportamientos adictivos, mal adaptativos y con rasgos disfuncionales en la vinculación afectiva en las relaciones de pareja y consiste en cómo cada individuo negocia y altera las preferencias personales y los comportamientos en favor de la relación amorosa y del otro (Castelló, 2000, 2005; Cloninger, 2003; Moral y Sirvent, 2008; Knee et al., 2008).

La persona dependiente presenta un patrón de necesidades emocionales no satisfechas que intenta cubrir de manera poco adaptativa, presentando un desequilibrio interno y tiene como característica presentar una autoestima muy baja (Castelló, 2000, 2005). Estas necesidades se suelen cubrir con la pareja, a la que idealiza y considera poderosa. La relación con la pareja está destinada a fracasar o a lograr un pobre equilibrio, porque la persona dependiente presenta un temor al abandono y al considerarse sola ante el peligro tiene la sensación de que no puede enfrentar el mundo si no están en compañía de otros.

Los comportamientos emitidos por una persona dependiente emocional afectan de manera directa a las relaciones de pareja e interpersonales. Tiene como consecuencia comportamiento asociados a la búsqueda de atención, en mantener la cercanía o en evadir ciertos 
eventos que puede considerar amenazantes, produciendo un desgaste en su calidad de vida y una necesidad de ser aprobado por parte de la pareja, temiendo a ser abandonados o a estar solos (Castelló 2000, 2005; Izquierdo y Gómez - Acosta, 2013). Asimismo, exagera los deseos positivos de querer estar con el otro, de contar con su apoyo y de sentirse queridos y valorados; así como, están en constante búsqueda de ayuda o consejos (Castelló, 2000, 2005; Cloninger, 2003; Lemos y Londoño, 2006).

\subsubsection{Características de la dependencia emocional}

Castelló (2000, 2005), distingue la dependencia en dos tipos: instrumental y emocional. En relación a la primera, se refiere a la carencia de autonomía e iniciativa en la vida diaria, las inseguridades, la búsqueda de apoyo social, dificultad para la toma de decisiones, asumir responsabilidades y desenvolverse con eficacia. Con respecto a la dependencia emocional, se caracteriza por demandas excesivas de afecto, relaciones interpersonales muy cercanas y relaciones de parejas donde predomina el desequilibrio, la sumisión y la idealización del otro, llevando a comportamientos excesivos de aferro y mucho temor a la soledad (Castelló, 2005).

Esta última incluye creencias sobrevaloradas acerca de la visión que tiene el individuo de sí mismo y de la relación con otros respecto a la amistad, la intimidad y la interdependencia, así como aquellas generadas por las relaciones cercanas e íntimas, por la soledad y la separación (Lemos y Lodoño, 2006; Moral y Sirvent, 2009).

Sin embargo, en la investigación de Knee et al. (2008) se afirma que no todas las formas en que se crea la interdependencia son iguales; estas varían de acuerdo a cada persona y al contexto en el que se desarrollen. A partir del grado en que uno es afectado por la relación, implica la tendencia a depender de la pareja para poder tener una validación personal positiva. Indica que la persona dentro de una relación puede ser influenciada o influenciable, y varía de acuerdo a la cercanía que se tenga con la pareja. Esto se debe a que los 
conocimientos, los recursos y los intereses de uno pueden influenciar a la pareja, llegando a modificar su forma de ser.

Dentro de la dependencia emocional se encuentran múltiples características. Entre ellas están: miedo a la ruptura, miedo e intolerancia a la soledad, prioridad de la pareja, necesidad de acceso a la pareja, deseos de exclusividad, subordinación y sumisión y deseos de control y de dominio (Aiquipa, 2012; Castelló, 2000, 2005).

Miedo a la ruptura

En la investigación realizada por Aiquipa (2015), se obtiene que una mujer con dependencia emocional suele experimentar elevados niveles de temor al pensar que puede haber una ruptura en su relación de pareja. Esto se debe a que tiene una preocupación no realista de ser abandonada o de tener que cuidar de sí misma, teniendo dificultades para demostrar un desacuerdo a su pareja por miedo a ser desaprobada y perder su apoyo, necesitando del otro para poder asumir ciertas responsabilidades en la mayoría de ámbitos de su vida (American Psychiatric Association, 2014; Castelló, 2000, 2005; Moral y Sirvent, 2009).

Miedo e intolerancia a la soledad

Es una de las características más distintivas y resaltantes. El individuo percibe que sólo en compañía de otro puede ser feliz y este temor se presenta con pensamientos irracionales recurrentes. Estos producen que la persona desarrolle estrategias interpersonales de control para mantener a la persona al lado e impulsa a querer estar continuamente con esta (Castelló, 2005; Lemos y Lodoño, 2006). Asimismo, se puede desarrollar el síndrome de abstinencia si no se tiene a la persona al lado, ya que es un malestar profundo que perjudica la calidad de vida ante el temor de perder a ese ser querido (Mayor, 2000).

Se evidencia, en otras investigaciones, que por más dañina que sea la relación, existe un miedo desproporcionado y una intolerancia a estar 
solo, teniendo una incapacidad para romper con las ataduras (Aiquipa, 2015; Castelló, 2005; Collins y Feeney, 2004; Moral y Sirvent, 2007). Luego de una ruptura, el dependiente emocional busca con urgencia otra pareja para que lo cuiden y apoyen, evitando el sentimiento de soledad (American Psychiatric Association, 2014; Castelló, 2000, 2005).

Prioridad en la pareja

Las personas con dependencia emocional tienen una prioridad en la pareja sobre cualquier cosa, ya que es considerada, de manera voluntaria, como el centro de su vida, la que le da sentido a su existencia y el objeto que más merece su atención (Castelló, 2005). Izquierdo y Gómez - Acosta (2013) en su investigación sobre dependencia afectiva, abordada desde una perspectiva contextual, afirma que las diversas conductas que el dependiente emocional tenga van a ser reforzadas por su pareja, tanto positiva como negativamente. Esta característica se presenta con mayor intensidad en la mujeres víctimas de la violencia de pareja (Aiquipa, 2015).

Necesidad excesiva del otro

Es la ilusión constante de tener acceso hacia la pareja (Castelló, 2000, 2005). Son los deseos de hablar con el otro, las llamadas insistentes y mensajes de texto, apariciones espontáneas e inoportunas en distintos ambientes, sentir una necesidad de impulso hacia su pareja siendo invasivo (Castelló, 2005).

Deseos de exclusividad

La persona dependiente emocional busca aislarse de su entorno social con la finalidad de dedicarse por completo a su pareja y tienen un sentimiento de posesión insaciable, esperando que el otro esté siempre a su disposición y haga lo mismo por él (Castelló, 2005). Cuentan con un anhelo irresistible y compulsivo de estar con la persona de la que depende a pesar de experimentar reacciones negativas en su ausencia (Aiquipa, 2015; Castelló, 2005; Moral y Sirvent, 2009). Collins y 
Feeney (2004), afirman en su investigación que suelen dejar de lado los intereses, amistades, obligaciones y necesidades personales para complacer, por medio de la atención exclusiva, a su pareja y hacerla sentir única y especial evitando discusiones o disgustos; esto mismo es respaldado en la investigación de Moral y Sirvent (2009) y por Castelló (2005).

Subordinación y sumisión

La persona dependiente tiene una imagen empobrecida de sí mismo y engrandecida del otro, produciendo un desequilibrio donde uno es sumiso y el otro dominante. Se puede llegar a realizar actividades que le desagradan a uno o que no comparte, por el simple hecho de hacer feliz al otro (APA, 2014). Esto es una característica relevante, sobre todo en mujeres que han sido víctimas de violencia, evidenciado en la investigación de Aiquipa (2015).

Deseos de control y dominio

El dependiente emocional modifica su conducta para recibir refuerzos positivos y asegurar la presencia de la pareja. El comportamiento de esta persona se dirige a evitar sentir el malestar que le ocasiona el no estar dentro de una relación y a las ganas de estar con una pareja sintiéndose acompañado (Castelló 2005; Moral y Sirvent, 2009).

\subsection{Autoestima}

\subsubsection{Definición de la autoestima general}

La autoestima es la evaluación o juicio que se tiene de uno mismo, es efectuada y mantenida por el individuo, expresando una actitud de aceptación incondicional o desaprobación e indicando la medida en que se cree capaz, valioso, con éxito e importante a pesar de errores, derrotas y fracasos (Coopersmith, 1987; Pereira, 2011; Rosenberg, 1979). Asimismo, es considerada como uno de los requisitos que tiene la persona para la manera de hablar, pensar, de sentir y de 
comportarse frente a distintos eventos (Coopersmith, 1987; Rosenberg, 1979; Orth, Robins, \& Widaman, 2012).

Se define también como la imagen que se tiene sobre uno mismo, formada por la percepción o autoconcepto y el ideal que tiene cada uno, la cual no es determinada, sino aprendida a partir del contacto con el ambiente familiar y el entorno social (Mora y Raich, 2005; Pereira, 2011; Riso, 2012b). Permite que se incorporen valores, reglas y costumbres, los cuales van a formar gran parte de su personalidad y se basa en todos los pensamientos y sentimientos que se han recogido, asimilado e interiorizado a lo largo de la vida, siendo la base para la toma de decisiones del día a día (Pereira, 2011). Sin embargo, para Orth et al. (2012), la autoestima es una causa, mas no una consecuencia de los eventos que ocurren en la vida de cada individuo.

\subsubsection{Niveles de autoestima general}

La autoestima general se forma de manera distinta e independiente en cada uno de acuerdo a sus experiencias de vida. Para Rosenberg (1979), la autoestima se puede categorizar en: alta, moderada y baja.

En la autoestima alta la persona se acepta y es capaz de definirse como buena. Permite al individuo ser autodeterminado, es decir, tener la capacidad de poder elegir las acciones libremente y ser valorado de manera positiva (Deci y Ryan, 2000). Según Rodríguez, Pellicer y Domínguez (2012) y Coopersmith (1987), tiene confianza en su propia competencia, éxito académico y social; asimismo, es íntegra, honesta y responsable. Como se valora positivamente y tiene confianza en su propia competencia, es capaz de respetar a los demás transmitiendo confianza y solicita ayuda cuando la necesita (Rodríguez et al., 2012).

Las personas con una alta autoestima saben controlar y afrontar la frustración y posponer algunos deseos, los cuales quisieron ser logrados a pesar de una serie de intentos, esfuerzos y actitudes adecuadas y no tuvieron un resultado exitoso (Ramírez, 2009). Acepta 
sus cualidades, tiene ganas de aprender y de participar en tareas nuevas, aumentando la seguridad personal y el bienestar tanto psicológico como físico (Baumeister, Campbell, Krueger y Vohs, 2003). Asimismo, muestran favoritismo en el grupo y comportamientos que los ayudan a mejorar sus relaciones interpersonales (Baumeister et al., 2003; Orth et al., 2012).

Los individuos con autoestima media son optimistas, pero en su interior sienten inseguridad en su valía personal y no llegan a aceptarse de modo pleno. Tienden a la búsqueda de aprobación social y experiencias que fortalezcan su autovaloración (Coopersmith, 1987). Cuando se encuentran en momentos de estabilidad, son capaces de mantener una valoración adecuada y positiva de sí; sin embargo, en los momentos de crisis, mantienen las características de la autoestima baja influyendo de manera negativa en las distintas dimensiones de su ser (Chávarry, 2008).

Por otro lado, los que presentan una baja autoestima se consideran inferiores al resto, suelen denigrar y degradar a los demás, así como proyectar sus propios sentimientos sobre los otros (Mora y Raich, 2005; Rodríguez et al., 2012). Asimismo, tiene una pobre valía personal porque están en una constante búsqueda de aprobación por parte del resto, presentan sentimientos de insatisfacción, son muy sensibles a la crítica, crean relaciones de dependencia con otros, suelen anticiparse hacia lo peor y sufrir explotación por parte de parejas, colegas o amigos (Coopersmith, 1987; Mora y Raich, 2005; Rodríguez et al., 2012).

Cuando la persona configura un autoesquema negativo sobre sí misma, suele mantenerlo por el resto de la vida si es que no hay esfuerzos por cambiarlo. De manera inconsciente, hará muchas cosas que confirmen y comprueben esos esquemas, así sean perjudiciales (Riso, 2012b). Estos harán que uno no se atreva a afrontar nuevos retos, debido a que la persona tiene temor y la limita a arriesgarse y buscar nuevas soluciones a los problemas, evitando las relaciones 
interpersonales y volviéndolas más disfuncionales; asimismo, está muy asociada a una mala imagen corporal (Mora y Raich, 2005; Orth et al., 2012; Riso, 2012b; Rodríguez et al., 2012).

La baja autoestima es un factor de vulnerabilidad o es un riesgo para la depresión (Orth et al., 2012). Asimismo, presenta una relación directa y está presente en distintos tipos de adicciones, no necesariamente relacionadas con el consumo de sustancias (Santamaría et al., 2015).

\subsubsection{Formación de la autoestima general en la vida de las personas}

Una de las principales influencias en la vida de una persona es la familia, porque se encarga de fortalecer la autoestima en cada uno de los miembros que la conforman (Ramírez, 2009). Según Mora y Raich (2005), los hijos de padres activamente implicados en la crianza de sus hijos suelen tener la autoestima más alta que los hijos de padres indiferentes o que están ausentes.

Cuando los hijos son maltratados, pueden entender el mundo de manera negativa o como si hubieran hecho algo malo para merecer tantos maltratos (Mora y Raich, 2005). No conocen el trato positivo y los lleva a formar una autoestima baja, donde se ven poco valorados y se consideran personas poco importantes (Acosta Padrón y Hernández, 2009).

Generalmente, los padres de familia y la sociedad son los que limitan el desarrollo del individuo, generando heridas importantes, las cuales reprimen las actuaciones naturales de la persona (Ramírez, 2009). Según Ramírez (2009, p. 20), “el individuo pensará de un modo y actuará de la forma que considere conveniente según la sociedad en la que viva y estará sometido a tensiones y nudos de estancamiento físicos que perjudicarán su salud y su sensación de bienestar”.

En la sociedad existen muchos prejuicios, los cuales conllevan a la formación y consolidación de la autoestima, ya que si una persona no es capaz de conseguir logros u objetivos, no puede sentirse valiosa 
(Ramírez, 2009). Sin embargo, esto no es completamente cierto, ya que muchas "personas que alcanzan éxitos notables en su profesión, negocios o carreras profesionales, no poseen una buena autoestima y otras que no han logrado sus objetivos se sienten valiosas y merecedoras de ser aceptadas por los demás” (Ramírez, 2009, p. 60).

\subsubsection{Autoestima Contingente}

Ha sido definida de diferentes maneras. Según Ryan y Brown (2003) y Deci y Ryan (1995), esta es una autoestima experimentada en individuos que se encuentran preocupados por aspectos de su valor o estima y cuya valía depende de alcanzar ciertos estándares como mostrarse de cierta forma o lograr algunas metas. No solo están determinados por eso, sino que también tienen una fuerte motivación por un deseo de sentirse valorados por ellos mismos y por los demás. Sus sentimientos de valía dependen de obtener ciertas contingencias (Roca, 2013). Se asume que esta valoración deriva o proviene de una relación crítica, inconsistente o que juzga mucho, la cual es de suma relevancia para el individuo y depende, generalmente, de los resultados externos (Deci y Ryan, 1995; Kernis, 2003; Kernis y Warschull, 1995).

Knee et al. (2008), en su investigación, define la autoestima contingente a las relaciones de pareja como una forma poco saludable de valoración a sí mismo, la cual depende de cómo se siente el individuo en concordancia a su relación de pareja y también puede ser conocida como autoestima dependiente. Esta se deriva de condiciones en las que se frustran los principios básicos de autonomía, competencia y relación (Deci y Ryan, 2000; Knee et al., 2008).

Además, Knee et al. (2008), manifiesta que si la autoestima es dependiente, la persona puede perder la capacidad de ejercer actividades de dominio autónomo impulsadas por el interés, la autenticidad y apertura hacia la información. Pero, cuando la autoestima es estable, uno puede experimentar presiones para realizar aquellas actividades que son de su interés. Evitan la exclusión de la 
pareja, por lo que buscan motivación para realizar conductas de aprobación del otro (Roca, 2013).

Asimismo, Knee et al. (2008) confirma que las personas que presentan altos niveles de autoestima contingente en las relaciones de pareja, perciben los eventos negativos que ocurren dentro de su relación, así sean pequeños, como significativos. Suelen reflejar una falta de autonomía, opinión personal y competencia al momento de participar en una relación.

Además, tienden a estar más pendientes de la opinión de los demás respecto a ellos mismos que de sus pensamientos íntimos $\mathrm{y}$ sentimientos. Suelen sentir una mayor ansiedad en eventos sociales porque presumen que los demás tendrán una evaluación negativa sobre ellos y son asociados con emociones negativas (Knee et al., 2008).

\subsection{Relación entre dependencia emocional y autoestima}

Dependencia emocional y autoestima general

En las investigaciones de Murray et al. (2000) y Luciano y Orth (2016), se obtuvo que los individuos con una alta autoestima general son más felices en su relación y la proyectan en su pareja viéndola de manera positiva, idealizándola y beneficiando al progreso de esta, así como se mantenían en relaciones más largas. Asimismo, se obtiene que la autoestima general sí es significativa entre las personas que estuvieron en una relación más larga en comparación a las que no (Luciano y Orth, 2016). Asimismo, la autoestima general (alta o baja) no era un factor significativo para el grupo de parejas casadas, así como para los que se mantenían en una relación.

Mayor (2000) y Castelló (2005) mencionan que la dependencia emocional puede ser causada y mantenida por la baja autoestima general y el pobre autoconcepto, por un déficit de asertividad al relacionarse con la pareja, escasas habilidades para la relación con problemas del día a día y del contexto familiar, carencia de estrategias de afrontamiento que la ayuden a calmar el síndrome de abstinencia al encontrarse sin la pareja. 
Además, Baker y McNulty (2013) afirman que las personas con una baja autoestima general y con un alto autoconcepto formado a partir de sus relaciones de pareja pueden expresar con mayor facilidad sus sentimientos de intimidad dentro de su relación. Ambas variables están asociadas con las conductas de riesgo que generan una alta dependencia emocional en parejas. Los resultados de una baja autoestima predijeron una ruptura de la relación al año siguiente, así como la autoestima general era más fuerte para las personas que se mantenían en relaciones largas (Luciano y Orth, 2016). Asimismo, en la investigación de Urbiola, Estévez, Iruarrizaga, y Jauregui (2017), se encontró que la dependencia emocional, específicamente las variables de evitar estar solo y necesidad de agradar, son predictores de la sintomatología de la autoestima general.

Baker y McNulty (2013) en su investigación acerca de la baja autoestima general y el riesgo de aumentar la dependencia emocional en el rol del autoconcepto formado a base de las relaciones, revela que las mujeres, en comparación de los hombres, presentan un mayor autoconcepto formado a partir de la relación de pareja, el cual se asocia de manera positiva con las personas que están por debajo de la media en autoestima general, más no se relacionó con las que presentaban una autoestima general por encima de la media. Además se manipuló de manera experimental al grupo de evaluación brindándoles información sobre su autoestima general y autoconcepto formado en base a las relaciones de pareja, permitiendo confirmar que las personas a pesar de su nivel de autoestima pueden involucrarse en las conductas que ponen en riesgo el rechazo del aumento de la dependencia emocional.

Por otro lado, en la investigación realizada por Orth, Erol, Ledermann y Grob (2018), se indica que la autoestima general no se ve influenciada por la pareja; sin embargo, esta sí se ve afectada de manera indirecta en el bienestar de la relación.

Dependencia emocional y Autoestima contingente a las relaciones de pareja 
En relación a los estilos de amor, Knee et al. (2008) indica que se relaciona una mayor autoestima contingente en la pareja cuando el estilo de amor es ansioso y maniático; sin embargo, en las relaciones menos dependientes mostraron poca o nula contingencia de autoestima de la relación. En el caso de las personas dominantes, estas suelen soportar de manera negativa los deseos y las situaciones que no resultan de la forma en que desean, carecen de generosidad y su ego se basa en sus caprichos (Ramírez, 2009). La autoestima contingente de una persona dominante suele estar muy herida, puesto que la vida no siempre le responde de la manera que desea y para sobrevivir intenta rodearse de personas que obedezcan su voluntad, como serían los dependientes emocionales (Ramírez, 2009).

En la investigación de Knee et al. (2008), se encontró que hay relación, aunque no muy marcada, entre la autoestima contingente en una relación con la autovaloración basada en la aprobación de terceros, el apoyo familiar, la apariencia personal y las competencias físicas e intelectuales. Asimismo, en relación a la autoestima contingente, se obtuvo que esta pueda aumentar con los eventos negativos de la pareja en una mayor escala, a diferencia de la disminución que esta tiene con eventos positivos.

Por último, Knee et al. (2008) muestra que la autoestima contingente y la pareja están relacionadas directamente a la autoestima general. También, que la autoestima contingente con un mayor grado dentro de una relación se ve asociada con más compromiso, acercamiento a la pareja y dependencia. Esto no trae mayores éxitos en la relación, sino que se refiere a que la persona está más enganchada a la pareja por miedo a lo que los demás piensen de ella, generando una mayor dependencia. 


\section{CAPÍTULO III: OBJETIVOS, HIPÓTESIS Y DEFINICIÓN DE VARIABLES}

\subsection{Objetivo(s)}

La presente investigación cuenta con dos tipos de objetivos: teóricos y psicométricos. En relación a los teóricos, están vinculados a los constructos de las pruebas utilizadas. Estos son:

- Describir la relación entre la dependencia emocional y la autoestima general en mujeres adultas en una relación de pareja de Lima Metropolitana.

- Describir la relación entre la dependencia emocional y la autoestima contingente a la relación de pareja en mujeres adultas en una relación de pareja de Lima Metropolitana.

Asimismo, la investigación cuenta con objetivos psicométricos en relación a las pruebas utilizadas: el Inventario de Autoestima de Rosenberg (Rojas-Barahona et al., 2009) y la Escala de Autoestima Contingente a las Relaciones de Pareja (Knee et al, 2008). Dichos objetivos son:

- Obtener evidencias de validez vinculadas al contenido mediante el juicio de expertos.

- Obtener evidencias de validez vinculadas a la estructura interna mediante el análisis factorial exploratorio.

- Obtener evidencias de confiabilidad mediante el método de consistencia interna.

\subsection{Hipótesis}

En la presente investigación existen dos hipótesis:

En primer lugar, hay una relación negativa entre la dependencia emocional y la autoestima general en mujeres adultas que se encuentran en una relación de pareja en Lima Metropolitana, sostenido por el modelo propuesto por Castelló (2000). En este modelo se explica que la baja 
autoestima es la responsable de la dependencia emocional, ya que la persona tiende a minimizar aspectos positivos de sí mismo o de su vida, manteniendo sentimientos negativos.

La segunda hipótesis de la investigación afirma que hay una relación positiva entre la dependencia emocional y la autoestima contingente a la relación de pareja en mujeres adultas en una relación de pareja de Lima Metropolitana. En la teoría de Deci y Ryan (2000), donde se mencionan tres necesidades psicológicas básicas de la autoestima: la autonomía, la relación y la competencia. Cuando una de estas se ve afectada, el individuo presenta dificultades respecto a su valía personal y se ven perjudicadas distintas áreas de su vida. Esto se respalda en la investigación de Knee et al. (2008), donde afirma que una persona con una alta autoestima contingente a las relaciones de pareja tiene falta de autonomía, carece de opinión personal y es poco competente, delegando el control de la relación a su pareja y la relación puede ir debilitando al individuo.

\subsection{Definición de variables}

3.3.1 Dependencia emocional: se refiere a la necesidad extrema de carácter afectivo que una persona siente por su pareja o compañero a lo largo de las relaciones que ésta tenga (Castelló, 2005). Se va a operacionalizar a través de los puntajes obtenidos en el Inventario de Dependencia Emocional (Aiquipa, 2012).

3.3.2 Autoestima General: es una actitud positiva o negativa que el individuo tiene hacia sí mismo, se expresa con actitudes de aprobación de desaprobación (Rosenberg, 1979). Se va a operacionalizar a partir del puntaje obtenido en la Escala de Autoestima de Rosenberg en la versión al español de RojasBarahona, Zegers y Förster (2009).

3.3.3 Autoestima Contingente a la Relación de pareja: actitud positiva o negativa que tiene el individuo sobre sí mismo, la cual depende de cómo se encuentra en su relación de pareja (Rosenberg, 1979; 
Knee et al., 2008). Se va a operacionalizar a partir del puntaje obtenido en la Escala de Autoestima Contingente a la Relación de Pareja de Knee et al. (2008). 


\section{CAPÍTULO IV: MÉTODO}

\subsection{Tipo y diseño de investigación}

Se trata de una investigación de tipo no experimental, ya que el estudio no manipula ninguna variable y los hallazgos encontrados no van a permitir establecer relación de causalidad entre las mismas (Hernández, Fernández y Baptista, 2014; Howitt y Cramer, 2011). Asimismo, el diseño es de tipo transversal y correlacional, por lo que los datos se recogieron en un momento determinado a un grupo de participantes y se analizó el grado de relación entre las variables (Hernández et al., 2014).

En relación a la recolección de datos, se utilizaron instrumentos psicométricos con la finalidad de ser adaptados al contexto peruano y de ser aplicados a futuras investigaciones (Hernández et al., 2014). Para esto, se han obtenido evidencias de validez de contenido de la Escala de Autoestima de Rosenberg; así como, evidencias de validez, vinculada a la estructura interna y al contenido, y de confiabilidad de la Escala de Autoestima Contingente a las Relaciones de Pareja.

\subsection{Participantes}

En la presente investigación, la población de estudio está conformada por mujeres que se encuentran en una relación de pareja entre los 18 y 45 años de Lima Metropolitana. Se eligió esta población porque en el Perú se realizó una encuesta a mujeres en edades fértil (15 a 49 años) por el Instituto Nacional de Estadística e Informática (INEI, 2016), donde indicó que el $57,5 \%$ de las entrevistadas se encontraban en una relación de pareja, el $31,3 \%$ de mujeres eran solteras y el $11,2 \%$ de mujeres eran divorciadas, separadas o viudas. Las participantes cumplen con los requisitos de la culminación de los estudios de primaria completa, estudiantes universitarias como de carreras técnicas, empleadas 
dependientes o independientes. Se excluyeron a aquellas que no se encontraron en una relación de pareja y no cumplieron con la culminación de los estudios primarios completos.

Por otro lado, el tamaño de la muestra se calculó a través del análisis a priori del programa G*Power (Faul, Erdefelder, Buchner, y Lang, 2009). En este se propuso realizar un análisis de correlación bivariada a una cola con un nivel de significancia de .05 y con una potencia estadística de .8 , valores ampliamente empleados en la investigación en ciencias sociales (Cohen, 1992; Lan y Lian, 2010).

El tamaño del efecto esperado fue establecido a partir de la sugerencia de Ferguson (2009) del tamaño mínimo recomendado para que tenga una implicancia práctica, que en el caso del coeficiente de correlación $r$ es de .20. De este modo, el tamaño mínimo de la muestra fue de 153 participantes.

Se utilizó el método no probabilístico de tipo intencional, debido a que se buscó un tipo específico de personas que presenten características de interés para las preocupaciones teóricas de la investigación, como lo fueron el sexo, la culminación de la primaria completa y el estar en una relación de pareja al momento de la evaluación (Howitt y Cramer, 2011). Inicialmente se evaluó a 185 mujeres; sin embargo se tomó la decisión de descartar las pruebas de 22 participantes. Esto se debe que algunas encuestas se mostraron incompletas, dejando páginas en blanco o algún ítem sin contestar. Finalmente, la muestra fue de 163 mujeres en una relación de pareja.

De las 163 participantes se obtuvo el promedio de la edad y el tiempo de duración de la relación en meses. En la Tabla 4.2.1 se pueden observar los datos mencionados previamente. 
Tabla 4.1

Características de la muestra

\begin{tabular}{lccc}
\hline \multicolumn{1}{c}{ Variable } & Mediana & Media & Desviación estándar \\
\hline Edad & 29.00 & 29.71 & 8.03 \\
Tiempo de duración de la & 46.00 & 69.33 & 66.81 \\
relación en meses & & & \\
\hline
\end{tabular}

*Se muestra el valor mínimo

Con respecto al nivel de educación, el 37,4\% presentó estudios superiores incompletos, el 39,9\% trabajadores dependientes y el 36,8\% se encuentran en una relación de pareja de tipo "enamorado". De la misma forma, se halló que el 35\% de las mujeres eran víctimas de violencia. El mayor porcentaje recibió violencia psicológica (31\%); luego, violencia física (22\%) y violencia de tipo sexual (5\%). Estos resultados coinciden con los evidenciados en el estudio de Aiquipa (2015) en una población similar, donde predominó la violencia psicológica en las mujeres.

\subsection{Técnicas de recolección de datos}

\section{Ficha Sociodemográfica}

Con la finalidad de recopilar datos relevantes para el estudio, se creó una ficha de datos donde se especificaba la edad, grado de instrucción y la ocupación. También se preguntó sobre tiempo de duración y el tipo de relación (enamorado, esposo, conviviente), si habían sido víctimas de violencia por parte de su pareja y el tipo de violencia recibida.

\section{Inventario de Dependencia Emocional de Aiquipa}

El Inventario de Dependencia Emocional (IDE) consta de 49 reactivos con una escala de Likert de cinco alternativas de respuesta, donde 1 punto se refiere a rara vez o nunca es mi caso y 5 puntos significa muy frecuente o siempre es mi caso (Aiquipa, 2012). Asimismo, está compuesto por siete factores: miedo a la ruptura (9 ítems), miedo e intolerancia a la soledad (11 ítems), prioridad de la pareja (8 ítems), necesidad de acceso a la pareja 
(6 ítems), deseos de exclusividad (5 ítems), subordinación y sumisión (5 ítems) y deseos de control y dominio (5 ítems) (Aiquipa, 2012, 2015). Esta fue aplicada en una población de 757 participantes de Lima Metropolitana.

Con respecto a la evidencias de validez vinculadas con el contenido los cinco expertos a los que fue expuesta la prueba, se mostraron de acuerdo en la relevancia de los ítems para evaluar las dimensiones establecidas (Aiquipa, 2012). Más del 95\% de los ítems reflejaron medir el constructo, siendo considerado como adecuados por todos los jueces expertos.

En relación a las evidencias de validez vinculadas con la estructura interna, el Test de Esfericidad de Barllet fue significativo, indicando la presencia de correlaciones pertinentes para poder llevar a cabo el análisis factorial exploratorio. Asimismo, se llevó a cabo la adecuación de las matrices de correlaciones utilizando el índice de Kaiser- Meyer-Olkin, donde se obtuvo un valor satisfactorio de .96 (Aiquipa, 2012). Se obtuvieron los siete factores, mencionados previamente, presentando autovalores mayores a 1 y explicado el $58.25 \%$ de la varianza de los datos originales (Aiquipa, 2012).

Se realizó una tercera evidencia de validez en Aiquipa (2012), vinculada a la diferencia de grupos contrastados, donde la prueba final fue aplicada a un grupo de 31 mujeres con dependencia emocional y tratamiento psicológico, y se le aplicó a un grupo no clínico. Se evidencia que existe una diferencia estadísticamente significativa entre ambos grupos al 95\% a un nivel de significancia de $<.001$.

Aiquipa (2012) brindó evidencias de confiabilidad a través del método de consistencia interna y el método de división de mitades usando los coeficientes Alfa de Crombach de .97 y el coeficiente $r$ de Pearson corregido con la fórmula Spearman-Brown y esta fue de .91. En la tabla 4.3.1 se pueden observar los coeficientes Alfa de Cronbach de cada uno de los factores de la escala. 
Tabla 4.2

Alfa de Cronbach de los factores del Inventario de dependencia Emocional

\begin{tabular}{|c|c|c|}
\hline Factores & Elementos & $\alpha$ de Cronbach \\
\hline Miedo a la ruptura & $\begin{array}{c}5,9,14,15,17, \\
22,26,27,28\end{array}$ & .88 \\
\hline Miedo e intolerancia a la soledad & $\begin{array}{c}4,6,13,18,19, \\
21,24,25,29, \\
31,46\end{array}$ & .89 \\
\hline Prioridad de la pareja & $\begin{array}{l}30,32,33,35 \\
37,40,43,45\end{array}$ & .86 \\
\hline Necesidad de acceso a la pareja & $\begin{array}{c}10,11,12,23 \\
34,48\end{array}$ & .87 \\
\hline Deseo de exclusividad & $\begin{array}{c}16,36,41,42 \\
49\end{array}$ & .79 \\
\hline subordinación y sumisión & $1,2,3,7,8$ & .76 \\
\hline Deseo de control y dominio & $\begin{array}{c}20,38,39,44 \\
47\end{array}$ & .77 \\
\hline
\end{tabular}

\section{Escala de Autoestima de Rosenberg (1965)}

Se utilizó el cuestionario con el permiso de los editores: The Morris Rosenberg Foundation, University of Maryland Department of Sociology (Rosenberg, 1989).

La escala de Autoestima de Rosenberg, se encarga de evaluar la apreciación positiva o negativa que tiene el individuo sobre sí mismo. Está conformada por 10 ítems, el 1, 3, 4, 7 y 10, han sido redactados de manera positiva; mientras que los ítems $2,5,6,8$ y 9, de manera negativa. Asimismo, se evalúa a partir de una escala de tipo Likert, donde 1 punto significa estoy muy en desacuerdo y 4 puntos se refiere a estoy muy de acuerdo (Rojas-Barahona et al., 2009). 
Con respecto a la confiabilidad, en el estudio de Rosenberg (1965) realizada con adolescentes estadounidenses, se halló una consistencia interna mediante un Alfa de Cronbach de .92.

En una investigación realizada por Gutiérrez (2015) con una población peruana, se evaluó la confiabilidad mediante el coeficiente alfa de Cronbach. En este la escala tuvo un índice de .733 y la correlación de ítem-test estuvo en un rango de .122 a .621, la cual es considerada como baja. Asimismo, en el estudio realizado por Castañeda (2013), se halló que la escala obtuvo un coeficiente alfa de Cronbach de .8 y correlaciones de ítem - test entre .33 y .59. El ítem 8 evidenció una discriminación de ítem - test de .17 .

En la presente investigación se utilizará la versión de Rojas-Barahona et al. (2009) adaptada en una población chilena, donde se demostró que el instrumento cuenta con evidencias de validez en relación con otras variables al presentar una correlación de .46 con el instrumento de satisfacción vital (LSI-A), que mide el bienestar subjetivo del individuo. La confiabilidad se halló con el Alfa de Cronbach y fue de .75.

Asimismo, en nuestro medio la adaptación de Rojas-Barahona et al. (2009) fue puesta en práctica por Darcout (2015) en una muestra de adultos jóvenes residentes en Lima, en la que los puntajes de la Escala de Autoestima de Rosenberg alcanzaron una confiabilidad de .90 e índices de discriminación a través de las correlaciones ítem-test entre .49 y .76.

En esta investigación se analizarán las evidencias de validez relacionadas al contenido de la prueba, mediante el análisis según el criterio de jueces expertos en términos de redacción y representatividad hacia la variable (Beaton, Bombardier, Guillemin y Bose Ferraz, 2007).

\section{Escala de Autoestima Contingente a las Relaciones de Pareja "Relationship-Contingent Self-Esteem Scale" de Knee et al.}

La escala de Autoestima Contingente a las Relaciones de Pareja (RSCE), creada en el 2008, consta de 11 ítems con una escala de Likert de cinco 
alternativas de respuesta, que van desde 1 Nada parecido a mí hasta 5 Muy parecido a mí (Knee et al., 2008).

Se obtuvo con el análisis factorial exploratorio, aplicado en una población de estudiantes de la Universidad de Houston en Estados Unidos, las evidencias de validez vinculadas al contenido las cuales presentaron cargas factoriales $>.50$ en todos los ítems. Esas se realizaron con dos muestras, una de 675 participantes y otra de 356 participantes, en ambos grupos eran mujeres que se encontraban dentro de una relación de pareja con un promedio de 22.2 años y se obtuvo una confiabilidad de .90 con la correlación múltiple cuadrara en ambos casos. Evidenció ser una prueba unidimensional ( Knee et al., 2008).

Asimismo, se realizó otra estimación de confidencialidad a partir del método test - retest, donde se obtuvo un coeficiente de estabilidad de .75 (Knee et al., 2008).

\subsection{Procedimiento de recolección de datos}

Se inició con el proceso de adaptación cultural y de traducción de la Escala de Autoestima Contingente a las Relaciones de Pareja. Se siguieron cinco pasos propuestos por Beaton et al. (2007).

En primer lugar, se realizó la traducción inicial en la que participaron dos traductores bilingües con lengua materna de español. El primer traductor, T1, estuvo informado sobre el tema de la investigación teniendo una perspectiva más clínica; el segundo traductor, T2, no tuvo conocimientos sobre la investigación y benefició para el uso de un lenguaje más coloquial. El segundo paso consistió en que una tercera persona sintetice ambas traducciones teniendo como resultado una traducción en común, T12. El tercer paso, fue la traducción a la inversa. En esta se contactó con dos traductores, BT1 y BT2, los cuales eran bilingües y tenían como lengua materna el inglés. Ninguno fue informado sobre los conceptos explorados y se buscó que traduzcan el cuestionario T-12 a la versión original. El cuarto paso consistió en reunir a un comité de expertos multidisciplinarios donde evaluaron todas las versiones traducidas de la 
escala principal. Asimismo, se llevó a cabo la evaluación de la equivalencia semántica, la equivalencia del idioma, la equivalencia de la experiencia y la equivalencia conceptual. En el último paso, se reunió a un comité de expertos, los cuales eran jueces para evaluar la validez de contenido de la prueba; es decir, que cada ítem mida el constructo propuesto calificándolo del 1 al 5. Al finalizar todos los pasos, la prueba estuvo lista para ser aplicada.

Con la finalidad de poder acceder a la muestra, se pidió autorización a una ONG, donde trabajaban con mujeres madres de familia, y a un proyecto social, donde se dictaban talleres acerca de la regulación de emociones, estilos de crianza y brindaba apoyo psicológico, para poder aplicar las pruebas. Asimismo se pidió apoyo a trabajadoras de diferentes instituciones públicas como privadas y a mujeres que cumplían con los criterios, explicándoles el objetivo y la utilidad de la investigación.

Una vez obtenido, se procedió a firmar el consentimiento informado y a la explicación de las pruebas a las participantes. En la resolución de las pruebas, no existe un tiempo límite.

El proceso de recolección culminó cuando se registraron a 163 mujeres adultas que estaban en una relación de pareja. 


\section{CAPÍTULO V: RESULTADOS}

\subsection{Análisis psicométricos}

En primer lugar, se obtuvieron las evidencias de validez vinculadas al contenido de la versión traducida y adaptada de la Escala de Autoestima Contingente a las Relaciones de Pareja (Knee et al., 2008) y de la Escala de Autoestima General (Rojas-Barahona et al., 2009). Se le entregó a 10 jueces expertos una plantilla con la finalidad de que evalúen la redacción y la representatividad de los ítems en relación a cada prueba, donde tomaron decisiones de manera independiente en con respecto a las evidencias de validez de contenido de cada ítem.

Para estimar las evidencias de validez vinculadas a la estructura interna se utilizó un análisis factorial exploratorio, ya que es uno de los métodos estadísticos más utilizados para poder evaluar las dimensiones de los instrumentos (Courtney, 2013; Fabrigar, Wegener, MacCallum y Strahan, 1999; Lloret-Segura, Ferreres-Traver, Hernández-Baeza, y Tomás-Marco, 2014). Se utilizó el programa estadístico Factor (Lorenzo-Seva y Ferrando, 2017) para poder analizar la dimensionalidad de la prueba, utilizando una matriz de correlación policórica porque es recomendada para ítems cuyo nivel de medición es ordinal y se asume que la variable latente presenta una desviación normal, para las pruebas con ítems politómicos (Burga, 2006).

Como método de extracción se utilizó el análisis de factor de rango mínimo (MRFA), considerado como uno de los que mejor funciona para obtener la aproximación del ideal de estimaciones que contienen una baja comunalidad de rango y permite determinar el rango mínimo de una matriz de covarianza o correlación y el mayor límite inferior a la confiabilidad de una prueba (Ten Berger y Kiers, 1991; Lorenzo-Seva, 2013). 
En cuanto a la rotación, se utilizó el método promín, recomendado para rotaciones oblicuas, debido a que permite obtener resultados más simples y completos, así como para determinar la relación teórica entre los factores y la prueba (Lorenzo-Seva, 2013).

Por último, con la finalidad de poder estimar las evidencias de la consistencia interna (Field, 2009) de la Escala de Autoestima Contingente a las Relaciones de Pareja (Knee et al., 2008), Escala de Autoestima General (Rosenberg, 1979) y el Inventario de Dependencia Emocional (Aiquipa, 2012), se utilizó el coeficiente Alfa de Cronbach y Alfa Ordinal para cada una. Se consideró trabajar con este último, ya que está basado en la matriz de correlación policórica y no en la covarianza de Pearson, es por eso que estima con mayor precisión alfa para la medición con ítems de tipo ordinal (Gadermann, Guhn y Zumbo, 2012).

5.1.1 Escala de Autoestima Contingente a las Relaciones de Pareja (Knee et al., 2008)

Para obtener las evidencias de validez vinculadas al contenido, se presentó una plantilla a 10 jueces con experiencia en psicología: clínica, dependencias e investigaciones psicométricas. A partir de las respuestas obtenidas, los resultados se procesaron de manera estadística usando el coeficiente V de Aiken, el cual mide el acuerdo interjueces, utilizando una escala de tipo Likert y considerando el criterio de exclusión de V <.80 señalado por Escurra (1989) y Aiken (1985). En la Tabla 5.1 se pueden observar los resultados donde se indica que la validez de contenido de los ítems oscila entre .85 y .94 , por lo que no fue necesario eliminar ninguno considerándose todos como significativos y representativos para el contenido que mide la escala. 
Tabla 5.1

Coeficiente $V$ de Aiken para los ítems de la Escala de Autoestima Contingente a las Relaciones de Pareja

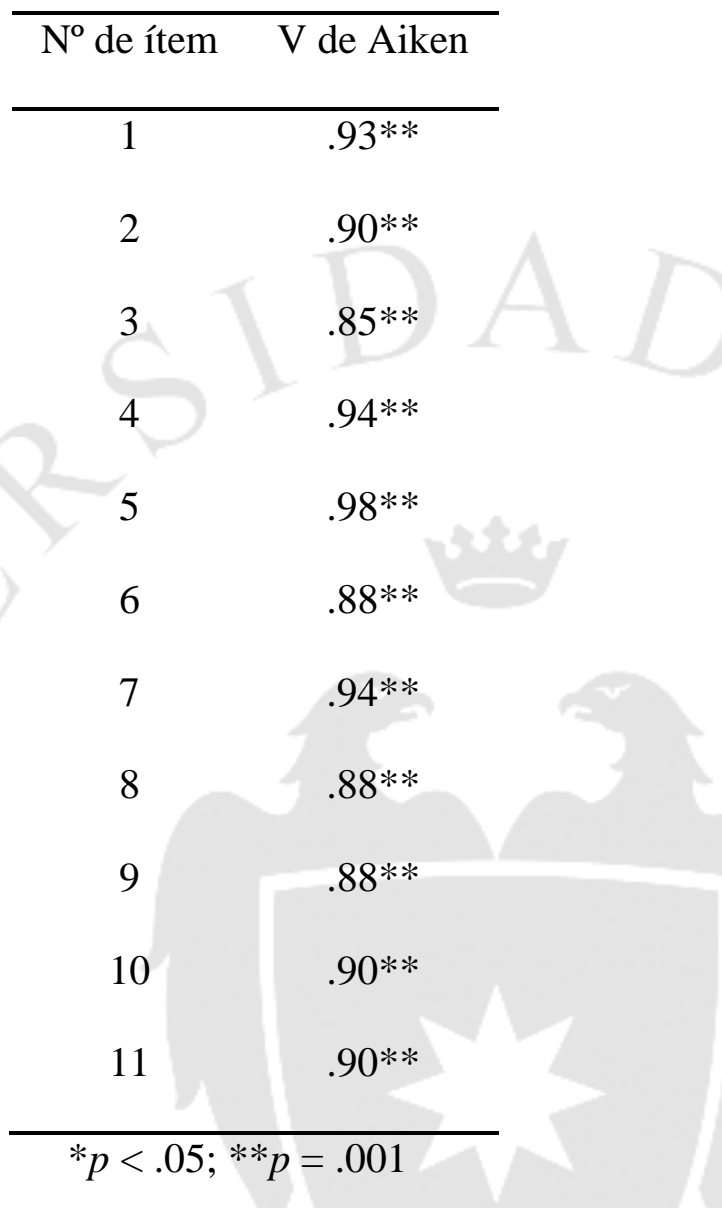

Con respecto a las evidencias de validez de la estructura interna de las puntuaciones de la prueba, se utilizó la medida de Kaiser-Meyer-Olkin (KMO) la cual indicó que existe una correlación suficientemente buena entre los ítems, $\mathrm{KMO}=.81$. En relación al test de esfericidad de Bartlett, se obtuvieron los resultados donde muestran que existe una relación estadísticamente significativa entre los ítems mostrando asociaciones entre ellos y se rechazó la hipótesis nula $X^{2}(163)=455.7, p<.001$ (Field, 2009). Al aparecer la presencia de un nuevo factor, se repitió el análisis de la prueba bajo el mismo procedimiento considerando dos factores. El KMO y el test de esfericidad de Bartlett se mantuvieron con valores adecuados; $\mathrm{KMO}=.81$ y $X^{2}(163)=559.8, p<.001$ (Field, 2009). En la 
tabla 5.2, se pueden observar las cargas factoriales de los ítems de la escala a dos factores.

Tabla 5.2

Cargas factoriales de los items que conforman la escala de Autoestima Contingente a las Relaciones de Pareja a dos factores

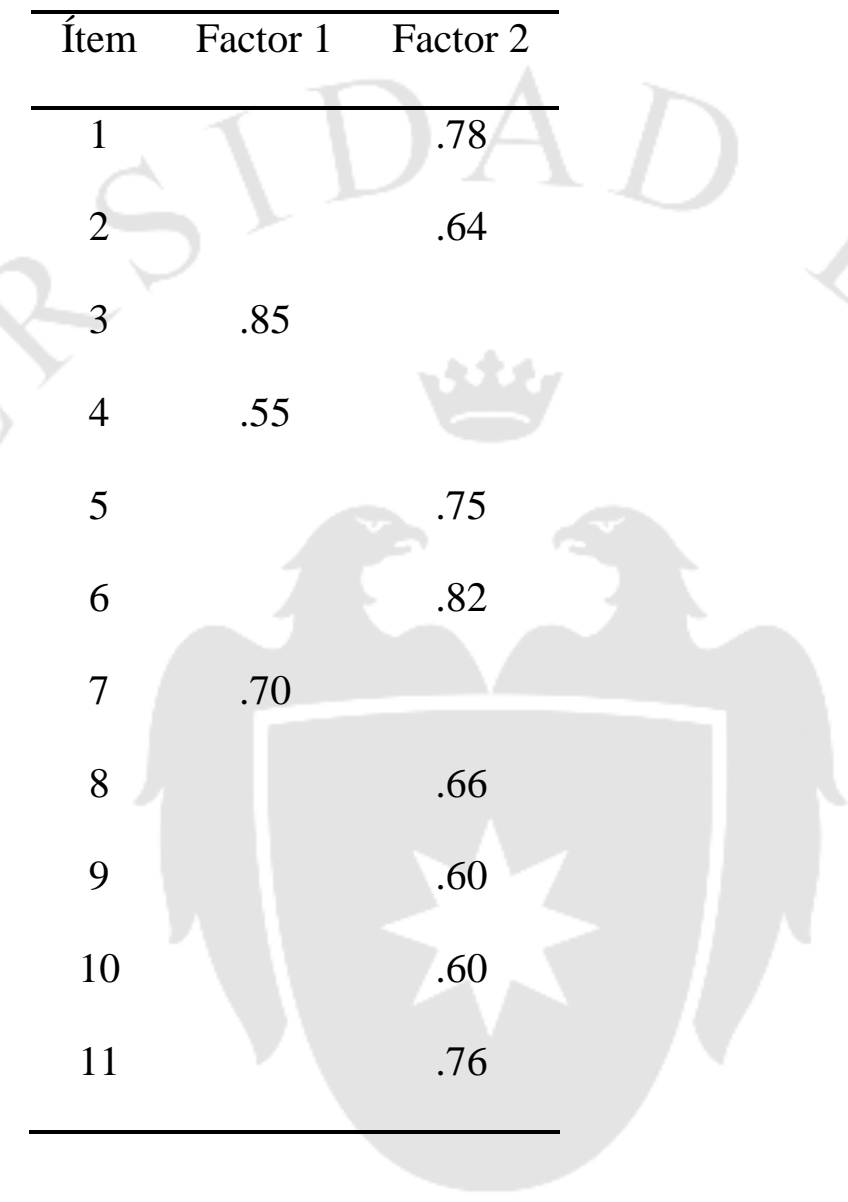

A pesar de que todos los ítems portaban cargas factoriales mayores a .30, se tomó la decisión de eliminar los ítems 3,4 y 7; debido a que estaban asociados a un nuevo factor el cual no contaba con soporte teórico para sustentarlo y no iba de acuerdo a la teoría de la versión original (Knee et al., 2008). Se realizó el análisis factorial exploratorio, de la misma manera, donde se obtuvo una estructura unidimensional. El KMO y el test de esfericidad de Bartlett continuaron con valores adecuados; $\mathrm{KMO}=.87$ y $X^{2}(163)=455.7, p<.001$ y una varianza común compartida que explica el $73.82 \%$ (Field, 2009). En la tabla 5.3 se presentan las cargas factoriales de los ítems de la estructura final de la escala. 


\section{Tabla 5.3}

Cargas factoriales de los ítems de la estructura final de la Escala de Autoestima Contingente a las Relaciones de Pareja

\begin{tabular}{ccc}
\hline Ítem & ACRP & $h^{2}$ \\
\hline 1 & .78 & .79 \\
2 & .66 & .62 \\
5 & .75 & .79 \\
6 & .83 & .83 \\
8 & .68 & .64 \\
9 & .63 & .57 \\
10 & .65 & .71 \\
11 & .76 & .69
\end{tabular}

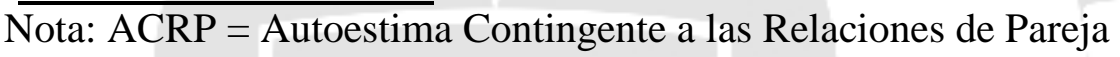

Luego, se estimó la consistencia interna a partir de la confiabilidad. Se obtuvo el coeficiente Alfa de Cronbach y Alfa Ordinal de .88, superando el mínimo recomendado de .70 (Hogan, 2004) y presenta un error estándar de medida $\mathrm{EEM}=2.53$.

Por otro lado, se hallaron las correlaciones ítem - test corregidas, las cuales superan el mínimo recomendado de .30, según Field (2009). En la Tabla 5.4 se pueden evidenciar los datos de la correlación ítem - test. 
Tabla 5.4

Correlación ítem - test corregida y alfa de Cronbach si el ítem es eliminado

\begin{tabular}{ccc}
\hline Ítem & $\begin{array}{c}\text { Correlación Item - Test } \\
\text { Corregida }\end{array}$ & $\begin{array}{c}\text { Alfa de Cronbach si el } \\
\text { ítem es eliminado }\end{array}$ \\
\hline 1 & .65 & .81 \\
2 & .53 & .83 \\
3 & .58 & .82 \\
4 & .68 & .81 \\
5 & .54 & .83 \\
6 & .50 & .83 \\
7 & .51 & .83 \\
8 & .62 & .82 \\
\hline
\end{tabular}

5.1.2 Escala de Autoestima General (Rojas-Barahona et al., 2009)

En relación a las evidencias de validez vinculadas al contenido se presentó a 10 jueces con experiencia en psicología: clínica, autoestima e investigaciones psicométricas, de los cuales se logró obtener 8 protocolos completos. Los resultados fueron procesados estadísticamente utilizando el coeficiente $\mathrm{V}$ de Aiken midiendo el acuerdo interjueces, utilizando una escala de tipo Likert y considerando el criterio de exclusión de $\mathrm{V}<.80$ (Aiken, 1985; Escurra, 1989). En la Tabla 5.5 se pueden observar los resultados donde se indica que la validez de contenido de los ítems oscila entre .81 y .91 , por lo que no fue necesario eliminar ninguno considerándose todos como significativos y representativos manteniendo la estructura original de la escala. 


\section{Tabla 5.5}

Coeficiente V de Aiken para los ítems de la Escala de Autoestima General

\begin{tabular}{cc}
\hline $\mathrm{N}^{\circ}$ de ítem & V de Aiken \\
\hline 1 & $.91^{* *}$ \\
2 & $.84^{* *}$ \\
3 & $.91^{* *}$ \\
4 & $.81^{* *}$ \\
5 & $.91^{* *}$ \\
6 & $.81^{* *}$ \\
7 & $.88^{* *}$ \\
8 & $.81^{* *}$ \\
9 & $.81^{* *}$ \\
10 & $.88^{* *}$ \\
\hline$* p<.05 ; * * p=.001$
\end{tabular}

En el análisis factorial exploratorio, para obtener las evidencias de validez relacionadas a la estructura interna, se obtuvo que existe una correlación suficientemente buena y significativa entre los ítems, $\mathrm{KMO}=.887 \mathrm{y}$ test de esfericidad de Bartlett $X^{2}(163)=632.8, p<.001$ (Field, 2009), demostrando evidencia empírica de un factor y explica el $71.9 \%$ de la varianza común compartida. En la tabla 5.6 se muestra las cargas factoriales de los ítems. 
Tabla 5.6

Cargas factoriales de los ítems de la estructura final de la prueba de Autoestima de Rosenberg

\begin{tabular}{ccc}
\hline Ítem & Autoestima General & $h^{2}$ \\
\hline 1 & .56 & .57 \\
2 & .89 & 1.00 \\
3 & .70 & .77 \\
4 & .73 & .80 \\
5 & .61 & .50 \\
6 & .84 & .81 \\
7 & .57 & .54 \\
8 & .45 & .46 \\
9 & .87 & .92 \\
10 & .81 & .79 \\
\hline
\end{tabular}

Por último, se estimó la consistencia interna a partir de la confiabilidad. Se obtuvo un Alfa de Cronbach de .86 y Alfa Ordinal de .90 con un error estándar de medida EEM = 1.85, superando el mínimo recomendado de .70 (Hogan, 2004).

Por otro lado, se hallaron las correlaciones ítem - test corregidas, estas superan el mínimo recomendado de .30, según Field (2009). En la Tabla 5.7 se pueden evidenciar los datos de la correlación ítem - test. 
Tabla 5.7

Correlación ítem - test corregida y alfa de Cronbach si el ítem es eliminado

\begin{tabular}{ccc}
\hline Ítem & $\begin{array}{c}\text { Correlación Item }- \\
\text { Test Corregida }\end{array}$ & $\begin{array}{c}\text { Alfa de Cronbach si el } \\
\text { ítem es eliminado }\end{array}$ \\
\hline 1 & .47 & .86 \\
2 & .74 & .84 \\
3 & .57 & .85 \\
4 & .57 & .85 \\
5 & .50 & .86 \\
6 & .72 & .84 \\
7 & .46 & .86 \\
\hline 8 & .37 & .87 \\
9 & .71 & .84 \\
\hline 10 & .68 & .84 \\
\hline
\end{tabular}

5.1.3 Inventario de Dependencia Emocional (Aiquipa, 2012)

Para el Inventario de Dependencia Emocional (Aiquipa, 2012) no fue necesario estimar las evidencias de validez vinculadas a la estructura interna y al contenido, ya que este fue creado y validado en Lima, Perú con una población similar.

Se estimó la confiabilidad por consistencia interna, donde se obtuvo un Alfa de Cronbach y un Alfa Ordinal de .97 con un error estándar de medida EEM = 6.42, superando el mínimo recomendado de .70 (Hogan, 2004).

Por otro lado, se hallaron las correlaciones ítem - test corregidas relacionándolas al factor que pertenece. Estas correlaciones superan el 
mínimo recomendado de .30, según Field (2009). En la Tabla 5.8 se pueden evidenciar los datos de la correlación ítem - test.

Tabla 5.8

Correlación ítem - test corregida y alfa de Cronbach si el ítem es eliminado

\begin{tabular}{|c|c|c|}
\hline Ítem & $\begin{array}{c}\text { Correlación Item - Test } \\
\text { Corregida }\end{array}$ & $\begin{array}{l}\text { Alfa de Cronbach si el } \\
\text { ítem es eliminado }\end{array}$ \\
\hline 1 & .57 & .97 \\
\hline 2 & .59 & .97 \\
\hline 3 & .49 & .97 \\
\hline 4 & .60 & .97 \\
\hline 5 & .74 & .97 \\
\hline 6 & .52 & .97 \\
\hline 7 & .51 & .97 \\
\hline 8 & .56 & .97 \\
\hline 9 & .66 & .97 \\
\hline 10 & .45 & .97 \\
\hline 11 & .55 & .97 \\
\hline 12 & .64 & .97 \\
\hline 13 & .58 & .97 \\
\hline 14 & .72 & .97 \\
\hline 15 & .72 & .97 \\
\hline 16 & .48 & .97 \\
\hline 17 & .77 & .97 \\
\hline 18 & .77 & .97 \\
\hline 19 & .68 & .97 \\
\hline 20 & .55 & .97 \\
\hline 21 & .72 & .97 \\
\hline 22 & .71 & .97 \\
\hline 23 & .40 & .97 \\
\hline 24 & .64 & .97 \\
\hline 25 & .73 & .97 \\
\hline
\end{tabular}




\begin{tabular}{|c|c|c|}
\hline Ítem & $\begin{array}{c}\text { Correlación Item - Test } \\
\text { Corregida }\end{array}$ & $\begin{array}{l}\text { Alfa de Cronbach si el } \\
\text { ítem es eliminado }\end{array}$ \\
\hline 26 & .73 & .97 \\
\hline 27 & .74 & .97 \\
\hline 28 & .65 & .97 \\
\hline 29 & .67 & .97 \\
\hline 30 & .60 & .97 \\
\hline 31 & .60 & .97 \\
\hline 32 & .67 & .97 \\
\hline 33 & .67 & .97 \\
\hline 34 & .50 & .97 \\
\hline 35 & .56 & .97 \\
\hline 36 & .60 & .97 \\
\hline 37 & .60 & .97 \\
\hline 38 & .61 & .97 \\
\hline 39 & .63 & .97 \\
\hline 40 & .63 & .97 \\
\hline 41 & .64 & .97 \\
\hline 42 & .57 & .97 \\
\hline 43 & .51 & .97 \\
\hline 44 & .61 & .97 \\
\hline 45 & .66 & .97 \\
\hline 46 & .69 & .97 \\
\hline 47 & .59 & .97 \\
\hline 48 & .68 & .97 \\
\hline 49 & .67 & .97 \\
\hline
\end{tabular}

5.2 Estadísticos Descriptivos

Se realizaron los análisis estadísticos descriptivos de las pruebas utilizadas en la investigación donde se logró obtener los promedios y los puntajes correspondientes a cada una. En la Tabla 5.9 se pueden evidenciar los resultados. 
Tabla 5.9

Estadísticos descriptivos y pruebas de normalidad de las puntuaciones de los cuestionarios para la muestra total $(N=163)$

\begin{tabular}{lcccccccc}
\hline Escalas & $M$ & $D E$ & Min. & Max. & $W$ & $p$ & Asim. & Curt. \\
& & & & & & & & \\
\hline ACRP & 25.86 & 7.46 & 8.00 & 40.00 & .964 & $<.001$ & -.363 & -.795 \\
AG & 29.82 & 5.78 & 13.00 & 40.00 & .968 & 0.001 & -.394 & -.600 \\
DE & 115.11 & 39.90 & 51.00 & 202.00 & .951 & $<.001$ & .387 & -.960 \\
\hline
\end{tabular}

Nota: ACRP = Autoestima Contingente a las Relaciones de Pareja; AG = Autoestima General; DE = Dependencia Emocional; Asim.$=$ Asimetría; Curt. $=$ Curtosis

Para los resultados mostrados previamente se llevó a cabo la prueba de bondad de ajuste debido a que se asume que provienen de una población que se distribuye normalmente. Se empleó la prueba de normalidad Shapiro-Wilk a la curva normal, debido a que se ha demostrado que presenta una mayor potencia estadística, permitiendo realizar el contraste del supuesto de normalidad y se puede utilizar con el tamaño de la muestra empleada (Razali y Wah, 2011; Saravia, 2014; Williams, Gómez y Kurkiewicz, 2013). Con respecto a los puntajes de las tres pruebas, los datos obtenidos rechazan la hipótesis nula indicando que provienen de poblaciones no distribuidas normalmente. Debido a esto, se utilizarán las correlaciones no paramétricas.

\subsection{Estadísticos Inferenciales}

La asociación de los puntajes de las pruebas se realizó a partir de la prueba rho de Spearman, debido a que presentaron una distribución no normal de la población (Field, 2009). Según los resultados, podemos observar la Tabla 5.10 y Tabla 5.11, donde todos los puntajes demuestran tener una relación estadísticamente significativa entre ellos (Ferguson, 2009). Asimismo, se puede determinar que la fuerza de la correlación es mediana, debido a que se encuentra entre .5 y .8 (Castillo-Blanco y Alegre, 2016; Cohen, 1992; Ferguson, 2009). 
En el caso de las puntuaciones de la prueba de Autoestima General (Rojas-Barahona et al., 2009), presenta una correlación positiva con la dependencia emocional y la autoestima contingente a las relaciones de pareja. Por el contrario, las variables dependencia emocional y autoestima contingente a las relaciones de pareja, presentan una correlación negativa entre ellas.

Por último, se realizó un análisis de la potencia estadística post hoc de cada una de las correlaciones con el programa estadístico $G^{*}$ Power (Cárdenas y Arancibia, 2014; Faul et al., 2009). Los puntajes de la potencia en todos los casos fue superior a .99, superando el mínimo recomendado y encontrándose dentro del criterio (Field, 2009).

Tabla 5.10

Coeficiente de Correlación Rho Spearman para las relaciones significativas de cada una de las escalas

\begin{tabular}{lccc}
\hline Escalas & ACRP & AG & DE \\
\hline ACRP & - & & \\
AG & $-.544^{* *}$ & - & \\
DE & $.662^{* *}$ & $-.684 * *$ & -
\end{tabular}

**Correlación es significativa en el nivel $\mathrm{p}<.01$

Nota: ACRP $=$ Autoestima Contingente a las Relaciones de Pareja; AG = Autoestima General; DE = Dependencia Emocional 
Tabla 5.11

Coeficiente de Correlación Rho Spearman por factores de la Escala de Dependencia Emocional

\begin{tabular}{lcc}
\hline \multicolumn{1}{c}{ DE } & AG & ACRP \\
\hline Miedo a la ruptura & $-.691^{* *}$ & $.592^{* *}$ \\
Miedo e intolerancia a la & $-.659^{* *}$ & $.643^{* *}$ \\
soledad & & \\
Prioridad de la pareja & $-.667^{* *}$ & $.572^{* *}$ \\
Necesidad de acceso a la & $-.431^{* *}$ & $.501^{* *}$ \\
pareja & & \\
Deseo de exclusividad & $-.510^{* *}$ & $.577^{* *}$ \\
subordinación y sumisión & $-.535^{* *}$ & $.516^{* *}$ \\
Deseo de control y dominio & $-.530^{* *}$ & $.550^{* *}$ \\
\hline ** Correlación es sionificativa en el nivel $\mathrm{p}<.01$ &
\end{tabular}

Nota: Pareja ACRP = Autoestima Contingente a las Relaciones de Pareja; $\mathrm{AG}=$ Autoestima General; DE $=$ Dependencia Emocional

\subsection{Análisis complementarios:}

A partir de la información recogida, se realizaron análisis complementarios a los planteados en los objetivos los cuales reflejan la relación de la violencia en las parejas con cada una de las pruebas aplicadas. Se utilizó la prueba de normalidad Shapiro-Wilk por grupos a la curva normal porque presenta una mayor potencia estadística y permite realizar el contraste del supuesto de normalidad (Razali y Wah, 2011; Saravia, 2014; Williams et al., 2013). Con respecto a las tres pruebas, se rechaza la hipótesis nula e indica que provienen de poblaciones no distribuidas normalmente. En la Tabla 5.12 se pueden observar los análisis. 
Tabla 5.12

Estadísticos descriptivos y normalidad de la variable violencia y los puntajes de las pruebas

\begin{tabular}{lcccccc}
\hline Violencia & \multicolumn{3}{c}{ Sí $(N=57)$} & & \multicolumn{3}{c}{ No $(N=106)$} \\
\hline Pruebas & $M$ & $D E$ & $W$ & $M$ & $D E$ & $W$ \\
DE & 128.21 & 39.46 & .218 & 108.07 & 38.50 & $<.001$ \\
AG & 27.68 & 5.36 & .120 & 30.96 & 5.68 & .001 \\
ACRP & 28.39 & 6.72 & .000 & 24.50 & 7.52 & .083 \\
\hline
\end{tabular}

Nota: Pareja ACRP = Autoestima Contingente a las Relaciones de Pareja; $\mathrm{AG}=$ Autoestima General; $\mathrm{DE}=$ Dependencia Emocional

Debido a los resultados de la tabla anterior, se utilizó la prueba U Mann Whitney para muestras independientes donde se evidencian diferencias estadísticamente significativas para las tres pruebas (Field, 2009). En relación a la prueba de dependencia emocional el rango promedio superior es de la violencia a la no violencia $(U=2118.00 ; Z=-3,143 ; p=.002)$; en el inventario de autoestima de Rosenberg, el rango promedio superior es la no violencia a la violencia de pareja $(U=1989.00 ; Z=-3,598 ; p=$ .000); y en la escala de autoestima contingente a las relaciones de pareja, el rango promedio superior es de la violencia a la no violencia ( $U=$ 2095.00; $Z=-3,226 ; p=.001)$. 


\section{CAPÍTULO VI: DISCUSIÓN}

En la presente investigación se buscó analizar las propiedades psicométricas de las puntuaciones derivadas de aplicar el Inventario de Autoestima de Rosenberg (Rojas-Barahona et al., 2009) y la Escala de Autoestima Contingente a las Relaciones de Pareja (Knee et al., 2008); así como, la existencia de una relación significativa entre las variables dependencia emocional y autoestima, diferenciándose en autoestima general y autoestima contingente a las relaciones de pareja. Estuvo compuesta por una muestra de 163 mujeres entre los 18 y 45 años que tenían como característica haber culminado los estudios de la primaria y encontrarse en una relación de pareja al momento de la evaluación. Además, se consideraron otras variables como ocupación, tiempo de relación, violencia en la pareja y el tipo de violencia recibida.

Se inició el proceso con la traducción y validación de Relationship Contingent Self Esteem Scale (Escala de Autoestima Contingente a las relaciones de Pareja) (Knee et al., 2008), ya que al no contar con evidencias de validez en el Perú se necesitaba justificar su uso a través de la recolección de nueva información (Eignor, 2013). Además, se siguieron una serie de consideraciones para lograr un adecuado proceso de adaptación de la prueba a partir de las mostradas en The Standards for educational and psychological testing (American Educational Research Association [AERA], American Psychological Association [APA], y National Council on Measurement in Education [NCME], 2014).

Se inició el proceso con los pasos propuestos por Beaton et al. (2007). Primero, se realizó la traducción del inglés al español por parte de dos traductores, donde solo uno fue informado sobre el tema. Luego de esto, se continuó con la unión de ambas traducciones y se envió a traducir nuevamente al inglés a dos traductores de lengua materna inglés. Después de haber tenido los documentos, se reunió a un comité de expertos, a los cuales se les presentó la prueba original en inglés y la versión final en español. 
Con el fin de evaluar las evidencias de validez vinculadas al contenido, se reunió a un comité de expertos que revisó los ítems e hizo algunas recomendaciones con respecto a la redacción en negativo, pero confirmaron estar de acuerdo con la traducción. Como todos los ítems superaron el valor mínimo de V de Aiken >.80 (Aiken, 1985; Escurra, 1989), fueron considerados para la aplicación en campo. Se tomó en cuenta el criterio y la opinión de jueces expertos porque verifican que la calidad del ítem no afecte la eficacia de medición de la prueba; así como, se guían de unas normas para poder emitir las juicios, críticas y recomendaciones (AERA et al., 2014; Eignor, 2013). Los ítems con algunas críticas sobre la redacción fueron el ítem 3 "Cuando mi relación va mal, mi autoestima no se ve afectada", ítem 4 "Si mi relación acabara mañana, no dejaría que eso afecte como me siento conmigo misma" y el ítem 7 "Mi autoestima no se ve afectada cuando las cosas van mal en mi relación. La redacción en negativo de estos puede haber influenciado en la comprensión de los mismos, por lo que la mejor decisión fue eliminarlos (Wolff y Preising, 2005; Moreno, Martínez y Muñiz, 2004).

En relación a las evidencias de validez vinculadas a la estructura interna, en la tabla 5.1.1.3 de la sección de resultados, al realizar los análisis se pudo comprobar mediante el análisis paralelo, técnica recomendada para hallar el número de factores de una prueba (Courtney, 2013), que la escala no presentaba la unidimensionalidad propuesta teóricamente por Knee et al. (2008) en su investigación. Debido a esto, se tomó la decisión de eliminar los tres ítems, porque pertenecían a un nuevo factor para el cual el contenido no permitía estructurarlo de manera flexible, impidiendo una interpretación adecuada de los resultados y que se replique el modelo original de la escala, esto mismo se evidencia en la investigación de Flores-Mazulis (2017). Asimismo, se consideraron las críticas de los jueces expertos sobre la redacción en negativo de los mismos como un factor relevante que pudo haber llevado a una confusión por parte de las evaluadas, complicando la lectura e interpretación (AERA et al., 1999; Moreno et al., 2004; Wolff y Preising, 2005). Es por eso que se 
recomienda no utilizar ítems directos e inversos dentro de una misma prueba porque confunde a las personas que responden teniendo un mayor nivel de dificultad para su comprensión, no evita sesgos y las propiedades psicométricas del test pueden verse afectadas (Simms, 2008; SuárezÁlvarez et al., 2018).

En relación a la prueba de Autoestima de Rosenberg (Rojas-Barahona et al., 2009), al no encontrar evidencias de validez dentro del contexto peruano, se decidió realizar un análisis factorial exploratorio para poder obtenerlas. Tal como se muestra en la sección de resultados, se confirmó que las evidencias de validez relacionadas a la estructura interna dentro de la población de estudio son adecuadas (Field, 2009). Asimismo, refleja el grado en el que la evidencia empírica y teórica mantienen la interpretación del puntaje de la misma, e implica que esta pueda medir el constructo al que pertenece, al igual que en la versión original (Rosenberg, 1965).

Ambas pruebas validadas presentan una estructura unidimensional midiendo un único atributo. Esta es una característica importante porque permite que el instrumento sea más confiable al no mostrarse sensible frente a la influencia de otro atributo que sesgue la respuesta del evaluado. Para lograr la unidimensionalidad, las pruebas deben ser construidas de manera cuidadosa y meticulosa, haciendo buenas estimaciones de medición de los atributos individuales, siendo convenientes para evaluar una serie de propósitos (Bond y Fox, 2015).

Con la finalidad de poder estimar la consistencia interna de las puntuaciones derivadas de aplicar la Escala de Autoestima Contingente a las relaciones de pareja (Knee et al., 2008), Autoestima General (RojasBarahona et al., 2009) y el Inventario de Dependencia Emocional (Aiquipa, 2012), se utilizó el coeficiente de Alfa Ordinal. Esto se debe a que es un método que permite estimar las evidencias de confiabilidad de una manera más exacta para escalas con respuestas de tipo policóricas o likert, como es el caso de las pruebas utilizadas, estimando con mayor precisión el alfa (Gadermann et al., 2012). Se tomó la decisión de no utilizar el Alfa de Cronbach, a pesar de ser uno de los métodos más 
aplicados, porque asume que los ítems son de intervalo llegando a subestimar la verdadera relación entre dos variables; así como, puede brindar una distribución sesgada de las respuestas asumiendo que todos los ítems miden lo mismo (Gadermann et al., 2012; Henson, 2001; Sijtsma, 2009).

En el caso de las evidencias de la consistencia interna de las puntuaciones derivadas del Inventario de Dependencia Emocional, usando los coeficientes de Alfa Ordinal, se obtuvieron resultados similares al del estudio de Aiquipa (2012) en la ciudad de Lima. Es recomendable realizar la confiabilidad de los instrumentos porque es una fuente de evidencia que permite establecer con exactitud la consistencia interna de la prueba y el error estándar de medida luego de haber sido aplicada a un grupo de personas y confirmar si los resultados son similares al ser replicada en una población similar (Gadermann et al., 2012; Henson, 2001).

En relación a las correlaciones ítem - test corregida, se realizó sobre cada una de las pruebas utilizadas en concordancia al factor que pertenecen. A partir de eso, se hallaron resultados donde se indica que superan el mínimo recomendado de .30 según Field (2009). Esta evidencia refiere que al existir buenas asociaciones de los ítems con los puntajes totales de los factores correspondientes, hay una buena capacidad de los ítems para diferenciar a las personas con altos y bajos niveles de la variable medida.

Con respecto a los análisis correlacionales, a partir de las teorías revisadas y del modelo propuesto por Castelló (2005), se esperó encontrar una relación negativa entre la dependencia emocional y la autoestima general. De manera similar, una relación positiva entre la dependencia emocional y la autoestima contingente a las relaciones de pareja (Knee et al., 2008).

Luego de haber obtenido los resultados de una muestra de 163 participantes, se rechazó la hipótesis nula ya que se encontraron los resultados esperados por las teorías planteadas y mencionadas previamente. Estos se presentan a pesar de que no haber investigación previa en nuestro contexto y luego de haber obtenido evidencias de validez derivadas de las puntuaciones. 
Haciendo referencia a la primera hipótesis, la relación entre la dependencia emocional y la autoestima general, se encuentra una correlación negativa estadísticamente significativa, cuyo tamaño del efecto puede ser clasificado entre moderado y grande (Ferguson, 2009). Se puede decir que a mayor dependencia emocional hay una menor autoestima general en mujeres en una relación de pareja. Esto coincide con la teoría propuesta por Castelló (2000, 2005), donde indica que la persona dependiente emocional tiene un desequilibrio interno y la caracteriza el presentar una baja autoestima; así como en la investigación de Sosa (2017), en una población en Lima con mujeres víctimas de violencia conyugal con y sin antecedentes de maltrato infantil, donde se evidencia una correlación similar entre ambas variables y en la investigación de Estevez, Urbiola, Iruarrizaga y Onaindia (2017).

Las personas que presentan una alta autoestima general son más felices en su relación y esto es proyectado de manera positiva en su pareja (Murray et al., 2000; Luciano y Orth, 2016). En cambio, las que presentan una baja autoestima general, suelen proyectar sus sentimientos sobre la pareja, teniendo dificultades para ser asertivos con ellos y para reaccionar de manera positiva al encontrarse sin la pareja (Castelló, 2005; Mayor, 2000; Mora y Raich, 2005). Cuando el individuo presenta alta dependencia emocional y baja autoestima tiende a permanecer mayor tiempo en la relación y se vuelve más tolerante y vulnerable a los abusos recibidos por parte de la pareja (De la Villa Moral, García, Cuetos y Sirvent, 2017; Pradas y Perles, 2012).

En relación a la segunda hipótesis, se encuentra una relación significativa y positiva entre la dependencia emocional y la autoestima contingente a las relaciones de pareja. Esto indica que cuando las mujeres en su relación de pareja son más dependientes emocionalmente, su autoestima va a depender de cómo esté yendo su relación.

A pesar de que no se encuentran investigaciones previas relacionando ambos constructos, se puede decir que las mujeres, al presentar un mayor auto concepto formado a partir de las relaciones de pareja, pueden cambiar 
la forma de verse a sí mismas de acuerdo a cómo esté su relación en un momento determinado (Baker y McNulty, 2013). Esto hace que la necesidad de la pareja incremente y la autoestima varíe de acuerdo a cómo se encuentre su relación.

La autoestima contingente puede aumentar con los eventos negativos que ocurren dentro de la relación, ya que al estar con personas dominantes, no siempre reaccionan de la manera esperada y para poder continuar con su relación, evitando que se llegue a una ruptura, obedecen a su pareja a pesar de que esté contra su voluntad (Knee et al., 2008; Ramírez, 2009). Sin embargo, cuando ocurren eventos positivos entre la pareja, la disminución de la autoestima contingente es mínima (Knee et al., 2008).

Por otro lado, se obtuvo las relaciones entre los factores de la dependencia emocional y la autoestima general, destacando los que presentaron una mayor correlación. En primer lugar se refleja que cuando la mujer pone a su pareja como prioridad, dejando de lado sus intereses y lo considera como el centro de su existencia, la autoestima que presenta es más baja (Castelló, 2005). Luego, el miedo e intolerancia a la soledad, considerado que solo en compañía del otro se puede ser feliz, tiene una relación alta con que la autoestima dependa de la relación de pareja. Se puede decir que mientras el miedo a estar solo sea mayor, la autoestima de la persona va a depender más de su pareja presentando incapacidad para romper con las ataduras, ya que se encuentra más enganchada a la pareja por temor al qué dirán de los demás y acercándose más al otro (Aiquipa, 2015; Castelló, 2005; Knee et al., 2008; Sosa, 2017).

En relación al miedo a la ruptura, es una variable que le produce mucha ansiedad a la persona dependiente como una consecuencia de la autoestima baja que presenta, buscando estar constantemente con la pareja evitando estar solos (Anguita, 2017; Bornstein, 2011; Castelló, 2000; 2005; Izquierdo y Gómez - Acosta, 2013).

A pesar de que no estaba dentro de los objetivos, se obtuvo la relación entre la autoestima general y la autoestima contingente a las relaciones de pareja, la cual es negativa. Como menciona Knee et al. (2008) en su 
investigación, la autoestima contingente y la pareja están relacionadas de manera directa con la autoestima general, la que siente un individuo en su vida cotidiana fuera de la relación. Cuando la autoestima contingente depende de la aprobación externa, en este caso de la pareja, y se percibe cierto riesgo de ser rechazado por el ser querido, la autoestima se verá afectada de manera temporal, viéndose perjudicado el bienestar psicológico del individuo y el desarrollo de sus relaciones interpersonales (Roca, 2013; Vonk y Smit, 2012). A partir de esto, se puede deducir que una persona con una baja autoestima general presenta una alta autoestima contingente en sus relaciones de pareja.

Por otro lado, se realizaron análisis complementarios en los que se encontraron relaciones estadísticamente significativas entre la violencia y la dependencia emocional y la autoestima. Los resultados reflejaron que cuando una mujer es víctima de violencia por parte de su pareja tiene una mayor dependencia emocional, una autoestima general menor y una mayor autoestima contingente. En investigaciones previas de Aiquipa (2015) y Villegas y Sánchez (2013), evidencian que en las relaciones de pareja los actos de violencia física, psicológica y sexual son muy frecuentes, pero que el miedo a la soledad, el miedo a la ruptura y la ansiedad de separación, son los factores que presentan mayor puntaje en relación a la dependencia emocional. Por el lado de la autoestima general, Labrador, Fernández-Velasco y Rincón (2010) y Matud (2004) apoyan los resultados de la presente investigación, afirmando que la autoestima general de las mujeres es más baja debido a la violencia que reciben, sintiéndose más inseguras y con menos apoyo por parte de su entorno social.

Si bien los resultados obtenidos contribuyen a darle un mayor sustento a la teoría de Castelló $(2000,2005)$ y a la inferencia o uso de las nuevas escalas en el contexto peruano, la investigación cuenta con algunas limitaciones para la interpretación.

En primer lugar, está la escasa o limitada bibliografía acerca de la relación de ambas variables: autoestima y dependencia emocional. Además, al ser 
un diseño de investigación relacional, no se pueden establecer relaciones de causalidad entre las variables.

Con respecto a la población, es un grupo reducido de mujeres que debe de cumplir algunos criterios clave como el estar en una relación de pareja y haber culminado los estudios de primaria. Asimismo, existen sesgos por deseabilidad social para evitar demostrar algún tipo de respuesta o conducta con la pareja, a pesar de ser confidencial.

Al realizar el proceso de traducción y validación de la escala de Autoestima Contingente a las Relaciones de Pareja (Knee et al., 2008), se encontró la limitación de que algunos ítems quedaron eliminados cambiando la estructura original de la prueba impidiendo realizar investigaciones con comparaciones transculturales; así como aplicaciones en otros contextos. Además, se encontró escaza literatura que sustente el constructo a evaluar, ya que es un término relativamente nuevo.

A pesar de todas las limitaciones mencionadas previamente, la presente investigación muestra hallazgos relevantes que son un aporte para la psicología. La dependencia emocional y su relación con la autoestima es una temática poco estudiada, por lo que la información brindada ayudará a darle un soporte a las teorías existentes, así como para futuras intervenciones psicológicas.

La adaptación lingüística de la Escala de Autoestima Contingente a las Relaciones de Pareja (Knee et al., 2008) es un aporte para el desarrollo de la psicología en el país. Esto se debe a que permitirá utilizarse la escala para las evaluaciones clínicas y ayudará a trabajar en la valoración que tiene un individuo en base a su relación de pareja, beneficiando su bienestar y logrando una mayor satisfacción personal.

Los resultados presentados son un acercamiento a lo que sería la relación entre ambas variables. Además, contribuirá a la prevención e intervención en los casos de una alta dependencia emocional y una baja autoestima en mujeres que se encuentren en una relación de pareja dentro del contexto 
peruano. Permite abrir una puerta para próximas investigaciones donde se aumente la variable de violencia en la pareja y el tipo que predomine.

Por último, se invita a que se siga investigando acerca de la relación de las variables, para así beneficiar al desarrollo de la psicología, brindándole un mayor sustento empírico y poder tomar medidas de prevención en las mujeres que se encuentran en una relación de pareja. 


\section{CONCLUSIONES}

- En cuanto a las evidencias de validez relacionadas a la estructura interna de la escala de Autoestima Contingente a las Relaciones de Pareja (Knee et al., 2008), no presentó una estructura factorial similar a la original.

- Al no tener la misma estructura que la prueba original, la aplicación de esta se verá limitado para contextos con poblaciones similares y no será útil para investigaciones transculturales (Vergara y Balluerka, 2000).

- En relación a las evidencias de validez vinculadas con la estructura interna de la escala de Autoestima de Rosenberg (Rojas-Barahona et al., 2009), presenta una estructura unidimensional, similar a la de la prueba original.

- La confiabilidad de las puntuaciones derivadas de los instrumentos utilizados fueron adecuadas, por lo que no hay un error de medición al aplicarlas.

- Las variables estudiadas presentaron correlaciones estadísticamente significativas entre ellas, cumpliéndose así las hipótesis planteadas: existe una correlación negativa entre la dependencia emocional y la autoestima general; $\mathrm{y}$ hay una correlación positiva entre la dependencia emocional y la autoestima contingente a las relaciones de pareja.

- Las dimensiones del Inventario de Dependencia Emocional (Aiquipa, 2012) que tuvieron una mayor correlación con la autoestima general y contingente fueron: prioridad en la pareja, miedo e intolerancia a la soledad y miedo a la ruptura con un tamaño del efecto entre mediano y grande. 
- La correlación entre la autoestima general y la autoestima contingente a las relaciones de pareja fue negativa y estadísticamente significativa con un tamaño del efecto mediano.

- La violencia en la pareja es una variable que se relaciona con la dependencia emocional y el nivel de autoestima con un tamaño del efecto pequeño.
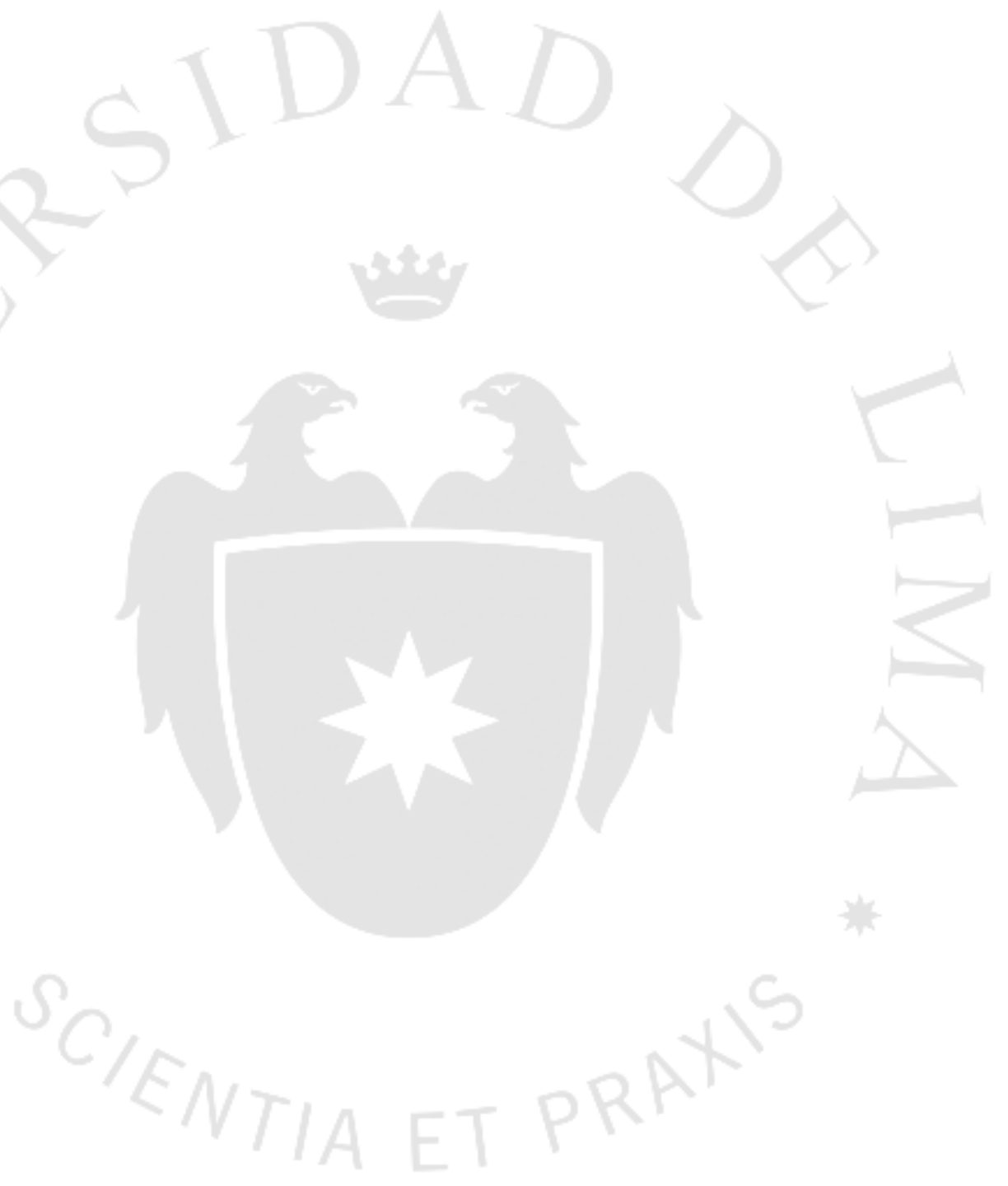


\section{RECOMENDACIONES}

A continuación, se especificarán las recomendaciones:

- Seguir investigando los constructos "dependencia emocional" y "autoestima contingente a las relaciones de pareja" para poder darle un mayor sustento teórico y valor a las pruebas utilizadas.

- Realizar investigaciones similares incluyendo la variable de violencia en la pareja, ya que es una población más susceptible a presentar una alta dependencia emocional, una baja autoestima general y una alta autoestima contingente a las relaciones de pareja.

- Utilizar los instrumentos con las versiones adaptadas al contexto peruano, ya que sus interpretaciones cuentan con evidencias de validez y sus puntuaciones son confiables. Esto permitirá ampliar el campo de investigación sobre la autoestima general y la autoestima contingente a las relaciones de pareja, y se podrán comparar los resultados con poblaciones de estudios similares permitiendo plantear nuevas intervenciones psicológicas; así como futuras estrategias de prevención.

- Utilizar la información de los resultados para innovar y mejorar las técnicas de intervención psicológica en pacientes mujeres con dependencia emocional y baja autoestima general que se encuentren en una relación de pareja. Esto tiene la finalidad de reducir el malestar psicológico que ambas variables producen en el individuo e ir buscando estrategias de prevención. 


\section{REFERENCIAS}

Acosta Padrón, R., y Hernández, J. (2009). La autoestima en la educación. Santiago de Chile: Red límite.

Aiken, L.R. (1985). Three coefficients for analyzing the reliability and validity of ratings. Educational and Psychological Measuremen, 45, 131-142. doi: $10.1177 / 0013164485451012$

Aiquipa, J. (2012). Diseño y validación del Inventario de Dependencia Emocional IDE. Revista de Investigación en Psicología (IIPSI), 15(2), 133-145.

Recuperado de http://sisbib.unmsm.edu.pe/bvrevistas/investigacion_psicologia/v15_n1/pdf/a8v 15n1.pdf

Aiquipa, J. (2015). Dependencia emocional en mujeres víctimas de violencia de pareja. Revista de Psicología, 33(2), 412-437. Recuperado de http://revistas.pucp.edu.pe/index.php/psicologia/article/view/13050/13663

American Educational Research Association, American Psychological Association, \& National Councilon Measurement in Education. (2014). Standards for educational and psychological testing. Washington, DC: American Educational Research Association.

American Psychiatric Association (2014). Guía de consulta de los criterios de diagnósticos del DSM-5. Barcelona: Medica Panamericana.

Anguita, A. (2017). Propuesta de intervención para la dependencia emocional. Superación de la dependencia tras la ruptura de la pareja (Tesis de Máster). Universidad Autónoma de Madrid, Madrid. Recuperado de https://repositorio.uam.es/bitstream/handle/10486/680162/anguita_corbo_alba_t fm.pdf?sequence $=1$

Baker, L., \& McNulty, J. (2013). When low self-esteem encourages behaviors that risk rejection to increase interdependence: The role of relational self-control. Journal of Personality and Social Psychology, 104(6), 995-1018. doi: $10.1037 / \mathrm{a} 0032137$ 
Baumeister, R. F., Campbell, J. D., Krueger, J. I., \& Vohs, K. D. (2003). Does high selfesteem cause better performance, interpersonal success, happiness, or healthier lifestyles? Psychological Science in the Public Interest, 4, 1-44. Recuperado de http://assets.csom.umn.edu/assets/71496.pdf

Beaton, D., Bombardier, C., Guillemin, F., \& Bose Ferraz, M. (2007). Recommendations for the Cross - Cultural Adaptation of the DASH \& QuickDASH Outcome Measures. Recuperado de http://www.dash.iwh.on.ca/sites/dash/files/downloads/cross_cultural_adaptation _2007.pdf

Boeckel, M.G., Blasco-Ros, C., Grassi-Oliveira, R., \& Martínez, M. (2014). Child abuse in the context of intimate partner violence against women: the impact of women's depressive and posttraumatic stress symptoms on maternal behavior. Journal of Interpersonal Violence, 29(7), 1201-1227. https://doi.org/10.1016/j.chiabu.2016.03.008

Bond, T.G., \& Fox, C.M. (2015). Applying the Rasch Model. Fundamental measurement in the human sciences. New York: Routledge.

Bornstein, R.F. (2011). An interactionist perspective on interpersonal dependency. Current Directions in Psychological Science, 20, 124-128. Recuperado de //doi.org/10.1177/0963721411403121

Burga, A. (2006). La unidimensionalidad de un instrumento de medición, perspectiva factorial. Revista de Psicología. Pontificia Universidad Católica. 25(1), 53-80. Recuperado de http://www.redalyc.org/pdf/3378/337829536003.pdf

Caballero, J., Alfaro, M., Nuñez, Y., y Torres, H. (2009). Violencia psicológica contra la mujer por su pareja en el Perú, 2004 - 2007. Revista Peruana de Epidemiología, $\quad 3, \quad 1-7 . \quad$ Recuperado de http://www.redalyc.org/pdf/2031/203120367006.pdf

Capafóns, J., y Sosa, D. (2015). Relaciones de pareja y habilidades sociales: el respeto interpersonal. Psicología Conductual, 23(1), 25-34. Recuperado de http://search.proquest.com/docview/1674473754/fulltextPDF/AEA15F0C27574 403PQ/1?accountid=45277

Cárdenas, M., y Arancibia, H. (2014). Potencia estadística y cálculo del tamaño del efecto en $\mathrm{G}^{*}$ Power: complementos a las pruebas de significación estadística y 
su aplicación en psicología. Salud \& Sociedad, 4(2), 210-224. Recuperado de https://dialnet.unirioja.es/servlet/articulo?codigo $=4945415$

Castañeda, A.K. (2013). Autoestima, claridad de autoconcepto y salud mental en adolescentes de Lima Metropolitana (Tesis de Licenciatura). Pontificia Universidad Católica del Perú, Lima. Recuperado de http://tesis.pucp.edu.pe/repositorio/handle/123456789/5094

Castelló, J. (Febrero - Marzo, 2000). Análisis del concepto de dependencia emocional. Conferencia I Congreso Virtual de Psiquiatría del 1 de Febrero. Recuperado de https://www.psiquiatria.com/congreso_old/mesas/mesa6/conferencias/6_ci_a.ht $\mathrm{m}$

Castelló, J. (2005). Dependencia emocional. Características y tratamiento. España: Alianza Editorial.

Castillo-Blanco, R., y Alegre, A. (2016). Importancia del tamaño del efecto en el análisis de datos de investigación en psicología. Persona, 18, 13748. Recuperado de https://revistas.ulima.edu.pe/index.php/Persona/article/viewFile/503/477

Chávarry, F.J. (2008). Correlación entre autoestima y rendimiento académico promedio en las áreas: Lógico matemática, Comunicación integral, Ciencias sociales, Ciencia tecnología y ambiente de los/as estudiantes de primer grado de secundaria de la institución educativa No. 81526 de Santo Domingo-Trujillo (Tesis de maestría). Universidad Cesar Vallejo, Lima. Recuperada de http://es.slideshare.net/besatrizpatriciachuquimantariinga/autoestima-yrendimiento-academico11

Clark, D.A. y Beck, A.T. (2012). Terapia cognitiva para trastornos de ansiedad. Bilbao: Desclée de Brouwer.

Cloninger, S. (2003). Teorías de la personalidad. México: Pearson Educación.

Cohen, J. (1992). A Power Primer. Psychological Bulletin, 22(1), 155-159. Recuperado de http://dx.doi.org.ezproxy.ulima.edu.pe/10.1037/0033-2909.112.1.155

Collins, N., \& Feeney, B. (2004). Working models of attachment shape perceptions of social support: evidence from experimental and observational studies. Journal of Personality and Social Psychology, 87(3), 363-383. doi: 10.1037/00223514.87.3.363 
Coopersmith, S. (1987). Self - esteem inventory adult form. San Francisco: CA: Freeman.

Courtney, M. (2013). Determining the number of factors to retain in EFA: using the SPSS R-Menu v2.0 to make more judicious estimations. Practical Assessment Research \& Evaluation, 18(8). Recuperado de https://pareonline.net/pdf/v18n8.pdf

De la Villa Moral, M., García, A., Cuetos, G. y Sirvent, C. (2017). Violencia en el noviazgo, dependencia emocional y autoestima en adolescentes y jóvenes españoles. Revista Iberoamericana de Psicología y Salud, 8(2), 96-107. Recuperado de https://doi.org/10.23923/j.rips.2017.08.009

Deci, E., \& Ryan, R. (1995). Human autonomy: The basis for true self-esteem. New York: Plenum.

Deci, E., \& Ryan, R. (2000). The "what" and "why" of goal pursuits: human needs and the self-determination of behavior. Psychological Inquiry, 11(4), 227-268. doi: 10.1207/S15327965PLI1104_01

Darcout, A.L. (2015). Claridad del autoconcepto, autoestima, autoreflexión e insight en adultos jóvenes residentes en Lima (tesis de licenciatura). Pontificia Universidad Católica del Perú, Lima. Recuperado de http://tesis.pucp.edu.pe/repositorio/bitstream/handle/123456789/6173/DARCO URT_MARQUEZ_ALVARO_CLARIDAD_AUTOCONCEPTO.pdf?sequence $=1$

Echeburúa, E., Amor, P.J., y De Corral, P. (2002). Mujeres maltratadas en convivencia prolongada con el agresor: variables relevantes. Acción Psicológica 2, 135-150. Recuperado de http://espacio.uned.es/fez/eserv/bibliuned:AccionPsicologica2002-numero20003/Documento.pdf

Eignor, D. R. (2013). The standards for educational and psychological testing. In K. F. Geisinger, B. A. Bracken, J. F. Carlson, J.-I. C. Hansen, N. R. Kuncel, S. P. Reise, \& M. C. Rodriguez (Eds.), APA handbooks in psychology. APA handbook of testing and assessment in psychology, Vol. 1. Test theory and testing and assessment in industrial and organizational psychology (pp. 245250). Washington, DC, US: American Psychological Association. Recuperado de http://dx.doi.org.ezproxy.ulima.edu.pe/10.1037/14047-013 
Escurra, L. (1989). Cuantificación de la validez de contenido por criterio de jueces. Revista de Psicología - PUCP, 6, 103-111.

Eskin, M., Ertekin, K., \& Demir, H, (2008). Efficacy of a problem-solving therapy for depression and suicide potential in adolescents and young adults. Cognitive Therapy and Research, 32, 227-245. doi: 10.1007/s10608-007-9172-8

Estevez, A., Urbiola, I., Iruarrizaga, I., \& Onaindia, J. (2017). Emotional dependency in dating relationships and psychological consequences of internet and mobile abuse. Anales De Psicología, 33(2), 260-268. doi:http://dx.doi.org/10.6018/analesps.33.2.255111

Fabrigar, L.R., Wegener, D.T., MacCallum, R.C., \& Strahan , R. J. (1999). Evaluating the use of exploratory factor analysis in psychological research. Psychological Methods, 4 (3), 272-299. Recuperado de http://hbanaszak.mjr.uw.edu.pl/TempTxt/FabrigarEtAl_1999_EvaluatingTheUs erOfExploratoryFactorAnalysisInPsychologicalResearch.pdf

Faul, F., Erdefelder, E., Buchner, A., \& Lang, A.G. (2009). Statistical power analyses using $G^{*}$ Power 3.1: Tests for correlation and regression analyses. Behavior Research Methods, 41(4), 1149-1160. doi: 10.3758/BRM.41.4.1149

Ferguson, C. (2009). An effect size primer: a guide for clinicians and researchers. Professional Psychology: Research and Practice, 40(5), 532-538. doi: $10.1037 / \mathrm{a} 0015808$

Field, A. (2009). Discovering Statistics Using SPSS (Third Edition). Dubai: SAGE.

Fiestas, F., y Piazza, M. (2014). Prevalencia de vida y edad de inicio de trastornos mentales en el Perú Urbano: resultados del estudio mundial de salud mental, 2005. Revista Peruana Médica Experimental y Salud Publica, 31(1), 39-47. Recuperado de http://www.scielo.org.pe/pdf/rins/v31n1/a06v31n1.pdf

Flores-Mazulis, M.F. (2017). Propiedades psicométricas de la escala de estrés cotidiano infantil en niños de 3ero a 5to grado de primaria de colegios de Lima Metropolitana. (Trabajo de investigación para optar el título de Licenciada en Psicología). Universidad de Lima, Lima. Recuperado de http://doi.org/10.26439/ulima.tesis/3571

Fromm, E. (1978). Tener y ser. Recuperado de http://www.enxarxa.com/biblioteca/FROMM\%20Tener\%20y\%20Ser.pdf 
Gadermann, A.M., Guhn, M., \& Zumbo, B.D. (2012). Estimating ordinal reliability for Likert-type and ordinal item response data: A conceptual, empirical, and practical guide. Practical Assessment, Research \& Evaluation, 17(3), 1-13. Recuperado de https://pareonline.net/pdf/v17n3.pdf

Gutiérrez, G. (2015). Claridad del autoconcepto, autoestima y bienestar psicológico en adolescentes de zonas urbano marginales (Tesis para Licenciatura). Pontificia Universidad Católica del Perú, Lima. Recuperado de http://tesis.pucp.edu.pe/repositorio/handle/123456789/6099

Heathers, G. (1955). Emotional dependence and independence in nursery school play. The Journal of Genetic Psychology, 87, 37-57. doi: 10.1080/00221325.1955.10532914

Henson, R.K. (2001). Understanding internal consistency reliability estimates: A conceptual primer on coefficient alpha. Measurement and Evaluation in Counseling and Development, 34(3), 177-189. Recuperado de http://psycnet.apa.org/record/2001-05693-005

Hernández, R., Fernández, C., y Baptista, M. (2014). Metodología de la investigación (6ta ed.) México D.F.: McGraw-Hill.

Hogan, T. P. (2004). Pruebas psicológicas: una introducción práctica. México: Manual Moderno.

Howitt, D. \& Cramer, D. (2011) Introduction to Research Methods in Psychology (3rd ed.). London: Prentice Hall.

Huerta, R., Ramírez, N., Ramos, J., Murillo, L., Falcón, C., Misare, M., Sánchez, J. (2016). Esquemas cognitivos disfuncionales y dependencia emocional en mujeres con y sin violencia en la relación de pareja de la ciudad de Lima. Revista de investigación en psicología, 19(2), 145-162. Recuperado de http://dx.doi.org/10.15381/rinvp.v19i2.12895

Instituto Nacional de Estadística e Informática (2016). Perú: Encuesta Demográfica y de Salud Familiar 2016: Nacional y Regional. Recuperado del sitio de Internet de Encuestas y Registros del Instituto Nacional de Estadística e Informática: https://www.inei.gob.pe/media/MenuRecursivo/publicaciones_digitales/Est/Lib 1433/index.html 
Izquierdo, S., y Gómez - Acosta, A. (2013). Dependencia afectiva: abordaje desde una perspectiva contextual. Psychologia: Avances de la disciplina, 7(1), 81-91. Recuperado de http://www.redalyc.org/articulo.oa?id=297226904011

Kernis, M. H. (2003). Toward a Conceptualization of Optimal Self-Esteem. Psychological Inquiry, 14(1), 1-26. Recuperado de http://dx.doi.org/10.1207/S15327965PLI1401_01

Kernis, M., \& Waschull, S. (1995). The interactive roles of stability and level of selfesteem: Research and theory. Advances in Experimental Social Psychology, 27(22), 93-14. doi: https://doi.org/10.1016/S0065-2601(08)60404-9

Knee, C., Bush, A., Canevello, A., \& Cook, A. (2008). Relationship-contingent S+selfesteem and the ups and downs of romantic relationships. Journal of Personality and Social Psychology, 95(3), 608-627. doi: 10.1037/0022-3514.95.3.608

Labrador, F.J., Fernández-Velasco, M.R. y Rincón, P. (2010). Características psicopatológicas de mujeres víctimas de violencia de pareja. Psicothema, 22(1), 99-105. http://www.psicothema.com/pdf/3702.pdf

Lan, L., \& Lian, Z. (2010). Application of statistical power analysis - how to determine the right sample size in human health, comfort and productivity research. Building and Environment, 45, 1202-1213. www.elsevier.com/locate/buildenv

Lemos, M., y Londoño, N. H. (2006). Construcción y validación del cuestionario de dependencia emocional en población colombiana. Acta Colombiana de $\begin{array}{llll}\text { Psicología, } & \text { 9(2), } & \text { 127-140. }\end{array}$ http://www.redalyc.org/articulo.oa?id=79890212

Lloret-Segura, S., Ferreres-Traver, A., Hernández-Baeza, A., y Tomás-Marco, I. (2014). El análisis factorial exploratorio de los ítems: una guía práctica, revisada y actualizada. Anales de Psicología, 30(3), 1151-1169. doi: http://dx.doi.org/10.6018/analesps.30.3.199361

Lorenzo-Seva, U. (2013). Why rotate my data using Promin? Technical Report. Department of Psychology, Universitat Rovira i Virgili, Tarragona. Recuperado de http://psico.fcep.urv.es/utilitats/factor/documentation/whypromin.pdf

Lorenzo-Seva, U., \& Ferrando, P.J. (2017). Factor Analysis.10.5 [Software de computación]. Recuperado de http://psico.fcep.urv.cat/utilitats/factor 
Luciano, E., \& Orth, U. (2016). Transitions in romantic relationships and development of self-esteem. Journal of Personality and Social Psychology, 112(2), 1-23. doi http://dx.doi.org/10.1037/pspp0000109

Matud, M. (2004). Impacto de la violencia doméstica en la salud de la mujer maltratada. Psicothema, 16(3), 397-401. Recuperado de http://www.psicothema.com/psicothema.asp?id=3009

Mayor, I. (2000). ¿Por qué siempre nos enamoramos de quién no debemos? Buenos Aires: Librería Argentina.

McKay, M., y Fanning, P. (1991). Autoestima. Evaluación y mejora. Barcelona: Martínez roca.

Ministerio de la Mujer y Poblaciones Vulnerables. (2017). Personas afectadas por hechos de violencia contra las mujeres, integrantes del grupo familiar y/o violencia sexual en los centros de violencia contra la mujer; según tipo de violencia, edad y sexo de la víctima. Periodo: Enero - Noviembre 2017 (Preliminar). Recuperado de: https://www.mimp.gob.pe/contigo/contenidos/pncontigoarticulos.php? codigo $=33$

Mora, M., y Raich, R. (2005). Autoestima. Madrid: Sintesis.

Moral, M., y Sirvent, C. (2007). Codependencia y género: análisis explorativo de las diferencias en los factores sintomáticos del TDS-100. Revista Española de Drogodependencias, 23(3), 90-91. Recuperado de http://www.aesed.com/descargas/revistas/v33n2_2.pdf

Moral, M., y Sirvent, C. (2008). Dependencias sentimentales o afectivas: etiología, clasificación y evaluación. Revista Española de Drogodependencias, 33(2), 150-167. Recuperado de http://www.aesed.com/descargas/revistas/v33n2_2.pdf

Moral, M., y Sirvent, C. (2009). Dependencia afectiva y género: perfil sintomático diferencial en dependientes afectivos españoles. Interamerican Journal of $\begin{array}{llll}\text { Psychology, } & \text { 43(2), } & \text { 230-240. }\end{array}$ http://www.redalyc.org/pdf/284/28412891004.pdf

Moreno, R., Martínez, R.J., Muñiz, J. (2004). Directrices para la construcción de ítems de elección múltiple. Psicothema, 16(3), 490-497. Recuperado de www.redalyc.org/articulo.oa?id=72716324 
Murray, S.L., Holmes, J.G., \& Griffin, D.W. (2000). The self-fulfilling nature of positive illusions in romantic relationships: love is not blind, but prescient. Journal of Personality and Social Psychology, 71, 1155-1180. doi: 10.1037//0022-3514.71.6.1155

Nezu, A.M., Nezu, C.M., y D’Zurilla, T.J. (2014). Terapia de solución de problemas: Manual de Tratamiento. Bilbao: Desclée de Brouwer.

Ortega Otero, M., Kendzierski, M., y Aranda Rubio, M.E. (2015). Intervención conductual en un caso de bajo estado de ánimo. Revista de Psicoterapia, 26(102), $175-188$. Recuperado de https://dialnet.unirioja.es/servlet/articulo?codigo=5399359

Orth, U., Erol, Y., Ledermann, T., \& Grob, A. (2018). Codevelopment of well-being and self-esteem in romantic partners: disentangling the effects of mutual influence and shared environment. Developmental Psychology, 54(1), 151-166. Recuperado de http://dx.doi.org/10.1037/dev0000400

Orth, U., Robins, R., \& Widaman, K. (2012). Life-span development of self-esteem and its effects on important life outcomes. Journal of Personality and Social Psychology, 102(6), 1271-1288. doi: 10.1037/a0025558

Pereira, M. (2011). Desarrollo personal y autoestima. Guía práctica para construir una personalidad. Bogotá: Ediciones de la U.

Pradas, E. y Perles, F. (2012). Resolución de conflictos de pareja en adolescentes, sexismo y dependencia emocional. Quaderns de Psicología, 14 (1), 45-60. doi 10.5565/rev/qpsicologia.1041

Quezada, N. (2014). Estadística con SPSS 22. Lima: Editorial Macro.

Ramírez, A. (2009). Autoestima para principiantes. Madrid: Ediciones Díaz de Santos.

Razali N. M., \& Wah Y. B. (2011). Power comparison of shapiro-wilk, kolmogorovsmirnov, lilliefors and anderson darling tests. Journal of Statistical Modelingand Analytics, 2(1), 21-33. Recuperado de http://www.de.ufpb.br/ ulisses/disciplinas/normality_tests_comparison.pdf

Riso, W. (2012a). Amar o depender. Barcelona: Planeta.

Riso, W. (2012b). Enamórate de ti. Barcelona: Planeta.

Roca, E. (2013). Autoestima sana. Valencia: ACDE. 
Rodríguez, M., Pellicer, G., y Domínguez, M. (2012). Autoestima: clave del éxito personal. México, D.F.: Manual Moderno.

Rojas-Barahona, C., Zegers, B., y Foster, C. (2009). La escala de autoestima de Rosenberg: validación para Chile en una muestra de jóvenes adultos, adultos y adultos mayores. Revista Médica de Chile, 137(6), 791-800. Recuperado de http://dx.doi.org/10.4067/S0034-98872009000600009

Román, I.A. (2011). La dependencia emocional en la depresión (Tesis de Maestría). Instituto Superior de Estudios Psicológicos. Recuperado de https://drive.google.com/file/d/0B_Rzkq9hb1dfRVdFY3d1T19mb0k/view

Rosenberg, M. (1965). Society and the adolescent self-image. Princeton, NJ: Princeton University Press.

Rosenberg, M. (1979). Conceiving the Self. Malabar, Florida: Krieger Publishing.

Rosenberg, M. (1989). Society and the Adolescent Self Image. Revised edition. Middletown, CT: Wesleyan University Press.

Ryan, R., \& Brown, K. (2003). Why we don't need self-esteem: on fundamental needs, contingent love, and mindfulness. Psychological Inquiry, 14(1), 27-82. Recuperado de http://selfdeterminationtheory.org/SDT/documents/2003_RyanBrown_Commen tPI.pdf

Santamaría, J.J., Merino, L., Montero, E., Cano, M., Fernández, T., Cubero, P.,... González Bueso, V. (2015). Perfil psicopatológico de pacientes con dependencia emocional. Revista Iberoamericana de Psicosomática, 116, 36-46. Recuperado de https://dialnet.unirioja.es/servlet/articulo?codigo=5288486

Saravia, J.C. (2014, Nov 16). Stats SOS [Blog Post]. Recuperado de https://statssos.net/2014/11/16/bienvenidos-amigos-psicologos/

Simms, L. (2008). Classical and Modern Methods of Psychological Scale Construction. Social and Personality Psychology Compass, 2(1), 414-433. doi 10.1111/j.1751-9004.2007.00044.x

Sijtsma, K. (2009). On the use, the misuse, and the very limited usefulness of Cronbach's Alpha. Psychometrika (74)1, 107-120. doi 10.1007/S11336-0089101-0

Sosa, D.B. (2017). Dependencia emocional y autoestima en mujeres víctimas de violencia conyugal con y sin antecedentes de maltrato infantil - San Juan de 
Lurigancho. Lima, 2017 (Tesis de Licenciatura). Universidad César Vallejo. Recuperado http://repositorio.ucv.edu.pe/bitstream/handle/UCV/11175/Sosa_DDB.pdf?sequ ence $=1 \&$ isAllowed $=\mathrm{y}$

Suárez-Alvarez, J., Pedrosa, I., Lozano, L., García-Cueto, E., Cuesta, M., \& Muñiz, J. (2018). Using reversed ítems in Likert scales: a questionable practice. Psicothema, 30(2), 149-158. doi: 10.7334/psicothema2018.33

Ten Berge, J. \& Kiers, H. (1991). A numerical approach to the approximate and the exact mimimum rank of a covariance matrix. Psychometrika, 56(2), 309-315. doi: 10.1007/BF02294464

Tortella-Feliu, M. (2014). Los trastornos de ansiedad en el DSM-5. Revista Iberoamericana de Psicomática, 110, 62-68. Recuperado de https://dialnet.unirioja.es/descarga/articulo/4803018.pdf

Urbiola, I., Estévez, A., Iruarrizaga, I. y Jauregui, P. (2017). Dependencia emocional en jóvenes: relación con la sintomatología ansiosa y depresiva, autoestima y diferencias de género. Revista Ansiedad y Estrés, 23(1), 6-11. Recuperado de https://doi.org/10.1016/j.anyes.2016.11.003

Vargas, H. (2017). Violencia contra la mujer infligida por su pareja y su relación con la salud mental de los hijos adolescentes. Revista Médica Herediana, 28(1), 48-58. Recuperado de https://doi.org/10.20453/rmh.v28i1.3074

Vergara, A.I., y Balluerka, N. (2000). Metodología en la investigación transcultural; perspectivas actuales. Psicothema, 12(2), 557-562. Recuperado de http://www.psicothema.com/pdf/625.pdf

Villegas, M. J., y Sánchez, N. (2013). Dependencia emocional en un grupo de mujeres denunciantes de violencia. Textos \& Sentidos, (7). Recuperado de http://biblioteca.ucp.edu.co/OJS/index.php/textosysentidos/article/view/807

Vonk, R., \& Smit, H. (2012). Optimal self- esteem is contingent: intrinsic versus extrinsic and upward versus downward contingencies. European Journal of Personality, 26(3), 181-188. Recuperado de https://doi.org/10.1002/per.817

Williams, M., Gómez, C. A., \& Kurkiewicz, D. (2013). Assumptions of multiple regression: correcting two misconceptions. Practical Assessment Research \& Evaluation, $\quad 18(11), \quad$ 1-14. Recuperado de http://pareonline.net/getvn.asp?v=18\&n=11 
Wolff, H. G., \& Preising, K. (2005). Exploring item and high order factor structure with the Schmid-Leiman solution: Syntax codes for SPSS and SAS. Behavior Research Methods, 37(1), 48-58. doi:10.3758/BF03206397 


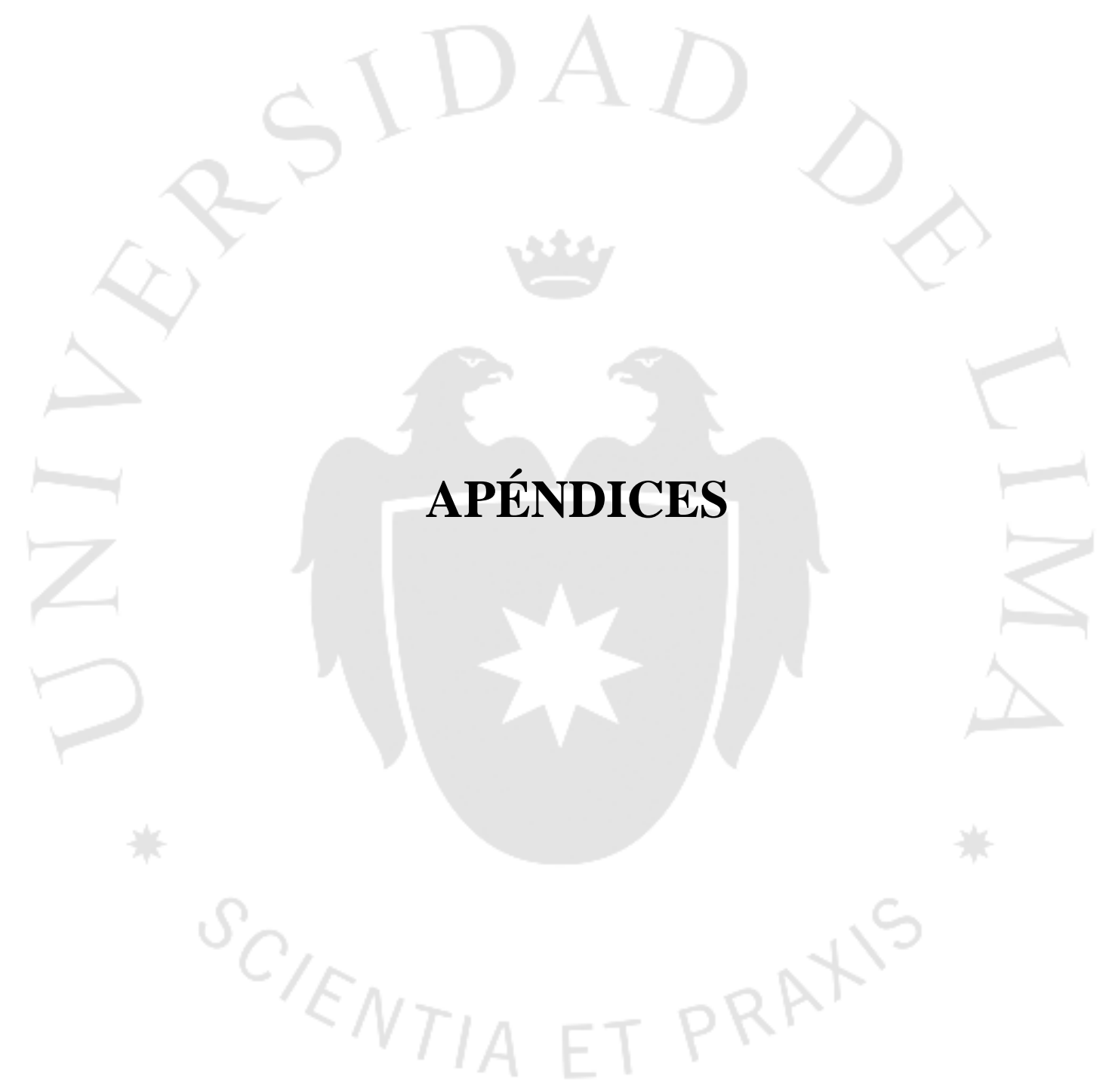




\title{
APÉNDICE 1: Ficha Sociodemográfica
}

\author{
Ficha de Datos
}

Edad:

Grado de Instrucción:

( ) Primaria completa

( ) Secundaria Incompleta

( ) Secundaria Completa

( ) Estudios superiores incompletos

( ) Estudios superiores completos

Ocupación:

( ) Estudiante

( ) Estudiante y trabajadora dependiente

( ) Estudiante y trabajadora independiente

( ) Trabajadora Dependiente

( ) Trabajadora Independiente

¿Actualmente te encuentras en una relación de pareja?

( ) Sí ( ) No

¿Qué tipo de relación tienes con tu pareja actual?

( ) Enamorado

( ) Novio

( ) Esposo

( ) Conviviente

( ) Libre

¿Cuánto tiempo de relación llevan? Años ...... Meses

¿Has sido víctima de violencia por parte de alguna de tus parejas?

( ) Sí

( ) No

¿Qué tipo de violencia has recibido? Puedes marcar más de 1 alternativa

( ) Física

( ) Psicológica

( ) Sexual

( ) Ninguna 


\section{APÉNDICE 2: Cuestionario de Autoestima de Rosenberg versión de Rojas-Barahona et al. (2009)}

A continuación encontrarás una lista de afirmaciones en relación a los sentimientos o pensamientos que tienes sobre ti. Marque con una X la respuesta que más te identifica.

\begin{tabular}{|c|c|c|c|c|}
\hline 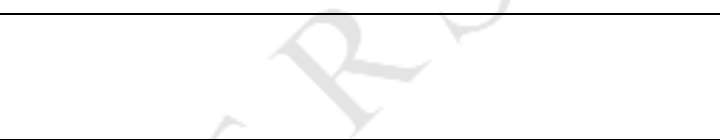 & $\begin{array}{c}\text { Muy en } \\
\text { desacuerdo }\end{array}$ & $\begin{array}{c}\text { En } \\
\text { desacuerdo }\end{array}$ & $\begin{array}{c}\text { De } \\
\text { acuerdo }\end{array}$ & $\begin{array}{l}\text { Muy de } \\
\text { acuerdo }\end{array}$ \\
\hline $\begin{array}{l}\text { 1. En general, estoy satisfecha conmigo } \\
\text { misma. }\end{array}$ & & & $v$ & \\
\hline $\begin{array}{l}\text { 2. A veces pienso que no soy buena para } \\
\text { nada. }\end{array}$ & & & & \\
\hline $\begin{array}{l}\text { 3. Creo que tengo un buen número de } \\
\text { cualidades. }\end{array}$ & & & & \\
\hline $\begin{array}{l}\text { 4. Soy capaz de hacer las cosas tan bien } \\
\text { como la mayoría de gente. }\end{array}$ & & & & \\
\hline $\begin{array}{l}\text { 5. Siento que no tengo muchos motivos } \\
\text { para sentirme orgullosa de mí. }\end{array}$ & & & & \\
\hline $\begin{array}{l}\text { 6. A veces me siento verdaderamente } \\
\text { inútil. }\end{array}$ & & & & \\
\hline $\begin{array}{l}\text { 7. Siento que soy una persona digna de } \\
\text { aprecio, al menos en igual medida que } \\
\text { los demás. }\end{array}$ & & & & \\
\hline $\begin{array}{l}\text { 8. Me gustaría poder sentir más respeto } \\
\text { por mí misma. }\end{array}$ & & & & \\
\hline $\begin{array}{l}\text { 9. En general, pienso que soy una } \\
\text { fracasada }\end{array}$ & & & & \\
\hline $\begin{array}{l}\text { 10. Tengo una actitud positiva hacia mí } \\
\text { misma. }\end{array}$ & & & & \\
\hline
\end{tabular}




\section{APÉNDICE 3: Escala de Autoestima Contingente a las Relaciones de Pareja adaptado por el presente estudio}

A continuación, se presentan una serie de enunciados relacionados con las características y actitudes personales. Por favor, lee cada enunciado con cuidado y evalúa en qué medida te identificas con las mismas. No existen respuestas correctas o incorrectas; por lo tanto, responde de la manera más honesta posible.

Indique en qué medida cada enunciado es verdadero para ti, de acuerdo con la siguiente escala:

$1 \longdiv { 2 } 2$

No me siento

23

$3 \quad 4$

5

identificada

Me siento un

poco identificada

Me siento muy

identificada

\begin{tabular}{|c|c|c|c|c|c|}
\hline $\begin{array}{l}\text { 1. Mi autoestima depende de qué tan bien esté } \\
\text { yendo mi relación. }\end{array}$ & 1 & 2 & 3 & 4 & 5 \\
\hline $\begin{array}{l}\text { 2. Me siento mejor conmigo misma cuando parece } \\
\text { que mi pareja y yo estamos conectados } \\
\text { emocionalmente. }\end{array}$ & 1 & 2 & 3 & 4 & 5 \\
\hline $\begin{array}{l}\text { 3. Mi sentido de valor como persona no se ve } \\
\text { afectado cuando mi relación va mal. }\end{array}$ & 1 & 2 & 3 & 4 & 5 \\
\hline $\begin{array}{l}\text { 4. Si mi relación acabara mañana, no dejaría que } \\
\text { eso afecte como me siento conmigo misma. }\end{array}$ & 1 & 2 & 3 & 4 & 5 \\
\hline $\begin{array}{l}\text { 5. Cuando mi relación va bien, me siento mejor } \\
\text { conmigo misma. }\end{array}$ & 1 & 2 & 3 & 4 & 5 \\
\hline $\begin{array}{l}\text { 6. Mi nivel de autoestima depende, en gran } \\
\text { medida, de que tan exitosa sea mi relación. }\end{array}$ & 1 & 2 & 3 & 4 & 5 \\
\hline $\begin{array}{l}\text { 7. Mi autoestima no se ve afectada cuando las } \\
\text { cosas van mal en mi relación. }\end{array}$ & 1 & 2 & 3 & 4 & 5 \\
\hline $\begin{array}{l}\text { 8. Cuando mi pareja y yo peleamos, me siento mal } \\
\text { conmigo misma. }\end{array}$ & 1 & 2 & 3 & 4 & 5 \\
\hline $\begin{array}{l}\text { 9. Me siento mejor conmigo misma cuando otras } \\
\text { personas me dicen que mi pareja y yo tenemos una } \\
\text { buena relación. }\end{array}$ & 1 & 2 & 3 & 4 & 5 \\
\hline $\begin{array}{l}\text { 10. Cuando mi pareja me critica o está decepcionado } \\
\text { de mí, me hace sentir muy mal. }\end{array}$ & 1 & 2 & 3 & 4 & 5 \\
\hline $\begin{array}{l}\text { 11. Me siento mejor conmigo misma cuando parece } \\
\text { que mi pareja y yo nos llevamos bien. }\end{array}$ & 1 & 2 & 3 & 4 & 5 \\
\hline
\end{tabular}




\section{APÉNDICE 4: Carta al Traductor 1 (T1)}

Traductor/Traductora

Presente.-

De mi consideración:

Teniendo en cuenta su experiencia como traductor/a oficial, tengo el agrado de dirigirme a usted para requerir de su servicio como traductor de la escala psicológica "Relationship-Contingent Self-Esteem Scale (Knee, Canevello, Bush \& Cook, 2008)". Se espera que esta sea adaptada y validada como parte de mi proyecto de tesis para obtener el Título Profesional de Licenciada en Psicología bajo la modalidad de Tesis.

La presente escala hace referencia a la autoestima contingente a las relaciones de pareja. Esta es definida como una valoración negativa o poco saludable que tiene el individuo sobre sí mismo que depende de cómo se encuentra la persona en su relación de pareja. Esta será aplicada en una muestra con una población de mujeres adultas jóvenes en una relación de pareja en Lima Metropolitana.

Le adjunto la escala a traducir.

De antemano agradezco su colaboración,

Giulia Camaiora Chiappe 


\section{APÉNDICE 5: Carta al Traductor 2 (T2)}

Traductor/Traductora

Presente.-

De mi consideración:

Teniendo en cuenta su experiencia como traductor/a oficial, tengo el agrado de dirigirme a usted para requerir de su servicio como traductor de la escala psicológica "Relationship-Contingent Self-Esteem Scale (Knee, Canevello, Bush \& Cook, 2008)". Se espera que esta sea adaptada y validada como parte de mi proyecto de tesis para obtener el Título Profesional de Licenciada en Psicología bajo la modalidad de Tesis.

Le adjunto la escala a traducir.

De antemano agradezco su colaboración, 


\section{APÉNDICE 6: Carta a Traductores Bilingües (BT1 y BT2)}

Traductor/Traductora

Presente.-

De mi consideración:

Teniendo en cuenta su experiencia como traductor/a oficial, tengo el agrado de dirigirme a usted para requerir de su servicio como traductor de la escala psicológica "Relationship-Contingent Self-Esteem Scale (Knee, Canevello, Bush \& Cook, 2008)". Esta ha sido traducida al español; sin embargo, necesito que esta sea traducida a su idioma original, el inglés. Se espera que esta sea adaptada y validada como parte de mi proyecto de tesis para obtener el Título Profesional de Licenciada en Psicología bajo la modalidad de Tesis.

Le adjunto la escala a traducir.

De antemano agradezco su colaboración,

Giulia Camaiora Chiappe 


\section{APÉNDICE 7: Carta para el Comité Multidisciplinario de Expertos}

Profesor/Profesora

Presente.-

Teniendo en cuenta su experiencia, tengo el agrado de dirigirme a usted para requerir de su participación como parte del "Comité Multidisciplinario de Expertos" en el proceso de adaptación de la escala psicológica "Relationship Connection (Knee, Canevello, Bush \& Cook, 2008)"'. Se espera que esta sea adaptada y validada como parte de mi proyecto de tesis para obtener el Título Profesional de Licenciada en Psicología bajo la modalidad de Tesis.

El proyecto de tesis es "Dependencia Emocional y Autoestima en mujeres adultas de Lima Metropolitana". Esta será aplicada en una muestra con una población de mujeres adultas que se encuentren en una relación de pareja.

La presente escala hace referencia a la autoestima contingente a las relaciones de pareja. Esta es definida como una valoración negativa o poco saludable que tiene el individuo sobre sí mismo que depende de cómo se encuentra la persona en su relación de pareja..

Asimismo se le pide revisar los siguientes documentos para poder realizar su evaluación de manera completa:

- Versión Original del Instrumento

- Traducción Directa (T1)

- Traducción Directa (T2)

- Síntesis de Traducciones (T12)

- Traducción Inversa 1 (BT1)

- Traducción Inversa 2 (BT2) 
Con la finalidad de poder lograr una equivalencia transcultural del instrumento, se le solicita tomar en consideración los siguientes criterios de equivalencia:

1. Equivalencia Semántica: Equivalencia en el significado de las palabras.

2. Equivalencia Idiomática: Si se encuentran frases coloquiales o idiomáticas en los ítems, se deben sustituir dichas expresiones por otras equivalentes al contexto a aplicar.

3. Equivalencia Empírica: La situación representada en cada uno de los ítems de la versión original debe encajar también en el contexto en el cual se está realizando la adaptación.

4. Equivalencia Conceptual: El concepto que se está explorando también debe ser válido en la cultura o contexto para el cual se está realizando la aplicación.

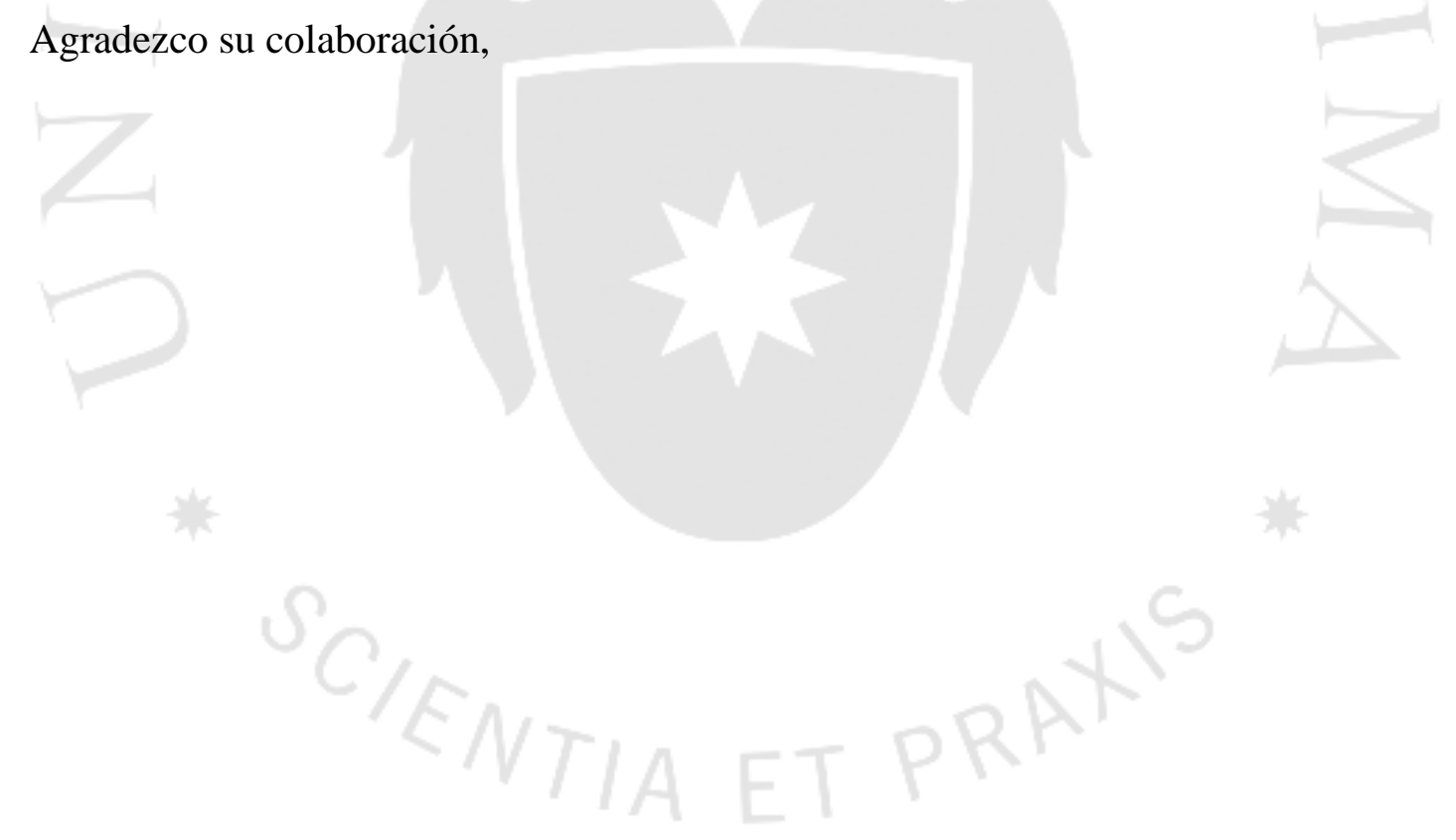

Giulia Camaiora Chiappe 


\title{
APÉNDICE 8: Formato de prueba a evaluar para el Comité Multidisciplinario de Expertos
}

\author{
Conexión de la Relación
}

A continuación, se presentarán una serie de enunciados relacionados con las características y actitudes personales. Por favor, lea cada enunciado con cuidado y evalúe en qué medida usted se identifica con las mismas. No existen respuestas correctas o incorrectas; por lo tanto, responda de la manera más honesta posible. Indique en qué medida cada enunciado es verdadero para usted, de acuerdo con la siguiente escala:

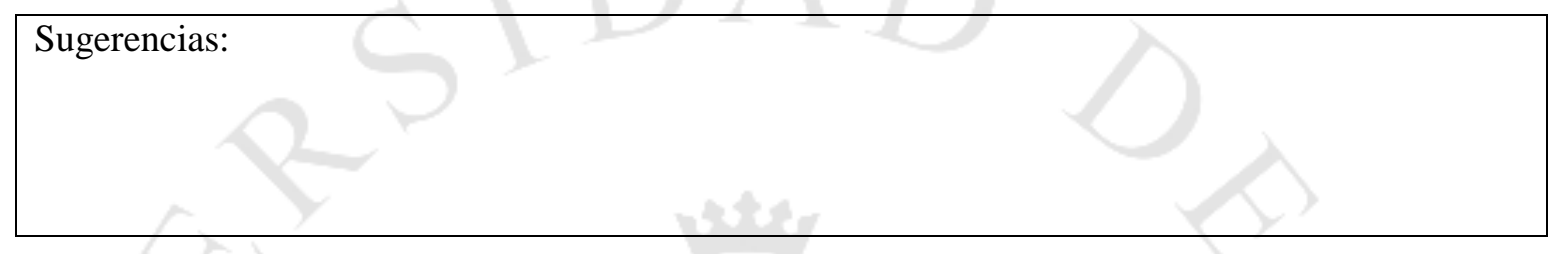

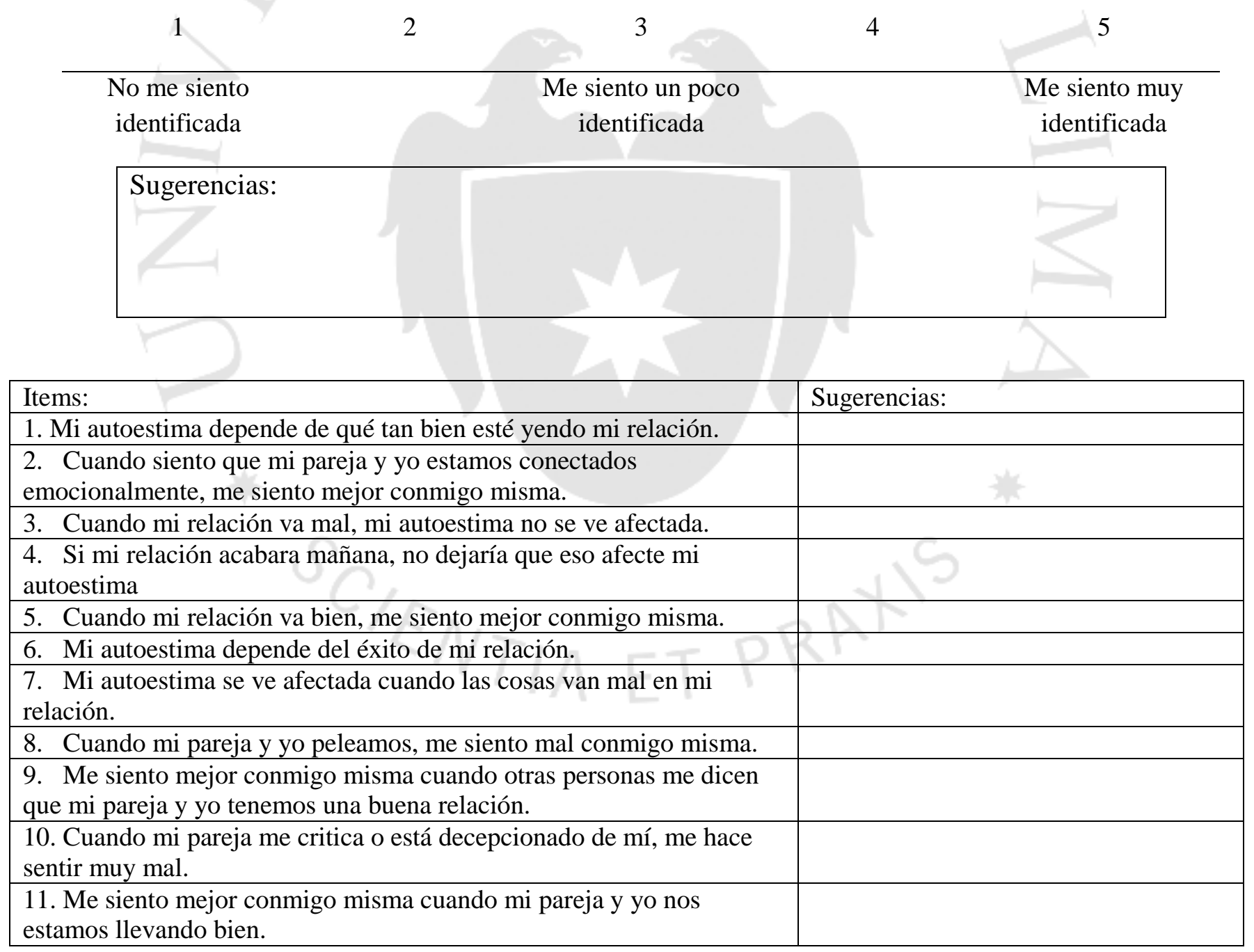




\section{APÉNDICE 9: Carta para Jueces Expertos}

Profesor/Profesora:

Presente.-

De mi consideración:

Teniendo en cuenta su experiencia; tengo el agrado de dirigirme a usted para solicitar su participación como juez experto en el proceso de validación de contenido de la escala psicológica "Relationship-Contingent Self-Esteem Scale (Knee, Canevello, Bush \& Cook, 2008)". Esta será adaptada y validada como parte de mi proyecto de tesis para obtener el Título Profesional de Licenciada en Psicología bajo la modalidad de Tesis.

El proyecto de tesis es "Dependencia Emocional y Autoestima en mujeres de Lima Metropolitana". Esta será aplicada en una muestra con una población de mujeres adultas de 18 a 45 años que se encuentren en una relación de pareja.

La presente escala hace referencia a la autoestima dependiente a las relaciones de pareja. Esta es definida como una valoración negativa o poco saludable que tiene el individuo sobre sí mismo que depende de cómo se encuentra la persona en su relación de pareja.

Agradezco su colaboración,

Giulia Camaiora Chiappe 


\title{
APÉNDICE 10: Formato de prueba a evaluar para Jueces Expertos
}

\author{
Relationship-Contingent Self-Esteem Scale
}

A continuación, según considere; marque en qué grado los ítems presentados evalúan el constructo explicado en la carta anterior.

Para cada ítem, se considerará la escala que va del 1 al 5:

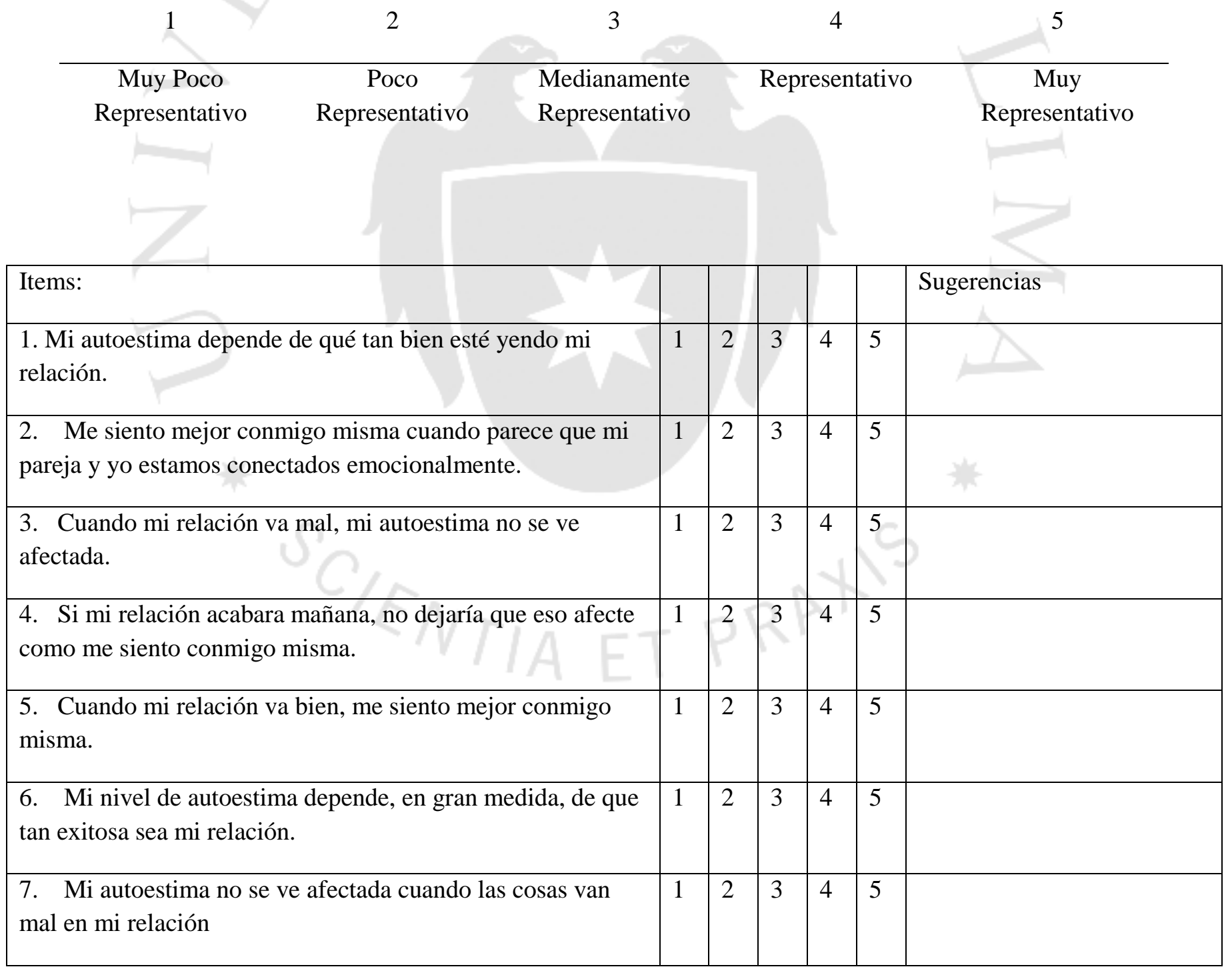




\begin{tabular}{|l|l|l|l|l|l|l|}
\hline $\begin{array}{l}\text { 8. Cuando mi pareja y yo peleamos, me siento mal conmigo } \\
\text { misma. }\end{array}$ & 1 & 2 & 3 & 4 & 5 & \\
\hline $\begin{array}{l}\text { 9. Me siento mejor conmigo misma cuando otras personas } \\
\text { me dicen que mi pareja y yo tenemos una buena relación. }\end{array}$ & 1 & 2 & 3 & 4 & 5 & \\
\hline $\begin{array}{l}\text { 10. Cuando mi pareja me critica o está decepcionado de mí, } \\
\text { me hace sentir muy mal. }\end{array}$ & 1 & 2 & 3 & 4 & 5 & \\
\hline $\begin{array}{l}\text { 11. Me siento mejor conmigo misma cuando parece que mi } \\
\text { pareja y yo nos llevamos bien. }\end{array}$ & 1 & 2 & 3 & 4 & 5 & \\
\hline
\end{tabular}




\section{APÉNDICE 11: Carta para Jueces expertos}

Profesor/Profesora:

Presente.-

De mi consideración:

Teniendo en cuenta su experiencia; tengo el agrado de dirigirme a usted para solicitar su participación como juez experto en el proceso de validación de contenido de la escala psicológica "Autoestima de Rosenberg". Esta será validada como parte de mi proyecto de tesis para obtener el Título Profesional de Licenciada en Psicología bajo la modalidad de Tesis.

El proyecto de tesis es "Relación entre la Dependencia Emocional y Autoestima: general y contingente en mujeres en una relación de pareja de Lima Metropolitana". Esta será aplicada en una muestra con una población de mujeres adultas de 18 a 45 años que se encuentren en una relación de pareja.

La presente escala hace referencia a la autoestima. Esta es definida como una actitud positiva o negativa que el individuo tiene hacia sí mismo, se expresa con actitudes de aprobación de desaprobación. Agradezco su colaboración,

Giulia Camaiora Chiappe 


\section{APÉNDICE 12: Formato de prueba a evaluar para Jueces Expertos}

Escala de Autoestima de Rosenberg

A continuación, según considere; marque en qué grado los ítems presentados evalúan el constructo explicado en la carta anterior.

Para cada ítem, se considerará la escala que va del 1 al 5:
1
2
3
4
5

\begin{tabular}{|c|c|c|c|c|c|c|}
\hline Muy Poco $\quad$ Poco & nan & & & \multicolumn{3}{|c|}{ Representativo $\begin{array}{c}\text { Muy } \\
\text { Representativo }\end{array}$} \\
\hline Items: & & 7 & 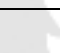 & & & Sugerencias \\
\hline $\begin{array}{l}\text { 1. En general, estoy satisfecha conmigo } \\
\text { misma. }\end{array}$ & 1 & 2 & 3 & 4 & 5 & 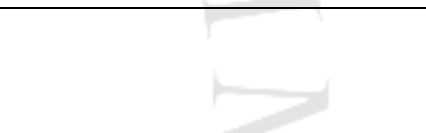 \\
\hline 2. A veces pienso que no soy buena para nada. & 1 & 2 & 3 & 4 & 5 & 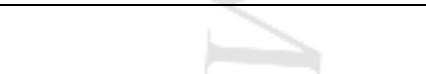 \\
\hline $\begin{array}{l}\text { 3. Creo que tengo un buen número de } \\
\text { cualidades. }\end{array}$ & 1 & 2 & 3 & 4 & 5 & \\
\hline $\begin{array}{l}\text { 4. Soy capaz de hacer las cosas tan bien como } \\
\text { la mayoría de gente. }\end{array}$ & 1 & 2 & 3 & 4 & 5 & \\
\hline $\begin{array}{l}\text { 5. Siento que no tengo muchos motivos para } \\
\text { sentirme orgullosa de mí. }\end{array}$ & 1 & 2 & 3 & 4 & 5 & \\
\hline 6. A veces me siento verdaderamente inútil. & 1 & 2 & 3 & 4 & 5 & 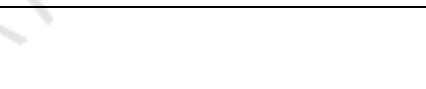 \\
\hline $\begin{array}{l}\text { 7. Siento que soy una persona digna de } \\
\text { aprecio, al menos en igual medida que los } \\
\text { demás. }\end{array}$ & 1 & 2 & 3 & 4 & 5 & \\
\hline $\begin{array}{l}\text { 8. Me gustaría poder sentir más respeto por mí } \\
\text { misma. }\end{array}$ & 1 & 2 & 3 & 4 & 5 & \\
\hline 9. En general, pienso que soy una fracasada & 1 & 2 & 3 & 4 & 5 & \\
\hline 10. Tengo una actitud positiva hacia mí misma. & 1 & 2 & 3 & 4 & 5 & \\
\hline
\end{tabular}




\section{APÉNDICE 13: Permiso del Inventario de Dependencia Emocional - IDE}

- Jesùs Joel Aiquipa Tello

para mí

Buenas tardes, srta. Giulia Camaiora.

Felicito su interés por investigar sobre este tema. Seguramente será una contribución muy importante.

En tal sentido, autorizo la utilización del Inventario de Dependencia Emocional-IDE con fines de investigación.

Le deseo muchos éxitos en estudio.

Atte.

Ps. Jesús Joel Aiquipa Tello

C.Ps.P. 16236

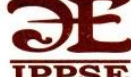

INSTITUTO PERUANO DE PSICOLOGÍA Y EDUCACIÓN

A QUIEN CORRESPONDA:

La presidenta del instituto Peruano de Psicología y Educación (IPPSE), deja constancia que:

La señorita Giulia Camaiora Chiappe, Bachiller en Psicología, adquirió el 9 de setiembre de 2016 el instrumento original de evaluación psicológica: Inventario de Dependencia Emocional (IDE), del autor Jesús Aiquipa Tello, publicado por nuestra editora Manual Moderno de México de la cual somos sus distribuidores autorizados.

Dicha adquisición autoriza a la señorita Camaiora, utitizar la prueba psicológica como instrumento de medida de la variable que estudia en su investigación.

Se extiende la presente constancia para los fines que considere de su interés.

San Isidro, 06 de diciembre de 2017

TIE INSTITUTO PERUANO DE

Rocaune

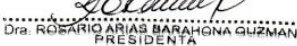

Iuan de Arona 776-A Of. 203 San Isidro - Lima 27 • Telf.: (51-1) 4408420 Cel.: 969105236 RPM: \#969105236 


\section{APÉNDICE 14: Permiso de la Escala de Autoestima de Rosenberg}

\section{Rosenberg Scale FAQ}

May I have permission to use the Rosenberg Self-Esteem Scale in my research?

Dr. Florence Rosenberg. Manny's wife, has given permission to use the Self-Esteem Scale for educational and professional research. There is no charge associated with the use of this scale in your professional research. However, please be sure to give credit to Dr. Rosenberg when you use the scale by citing his work in publications, papers and reports. We would also appreciate receiving copies of any published works resulting from your research at the University of Maryland address listed below.

How do I cite the scale?

You should cite the scale according to the standards of your discipline. The most appropriate citation is: "Rosenberg, Morris. 1989. Society and the Adolescent Self-Image. Revised edition. Middletown, CT: Wesleyan University Press."

Giulia Camaiora <giucamaiora@gmail.com>

para crojash .

...

Buenas tardes Sr. Cristián

Soy Giulia Camaiora Chiappe, bachiller en Psicologia de la Universidad de Lima.

Estoy haciendo una investigación sobre la relación entre la dependencia emocional y la autoestima. Para esta, utilizaré el Inventario de Autoestima de Rosenberg, pero quisiera pedir autorización para poder utilizar la versión que ustedes adaptaron en su investigación: "La escala de autoestima de Rosenberg: Validación para Chile en una muestra de jóvenes adultos, adultos y adultos mayores".

Agradezco su respuesta,

Giulia Camaiora

Cristian A. Rojas Barahona

Q parami -

por supuesto Giulial que todo salga bien, y ojalá puedas compartir los resultados.

saludos

Cristian

\section{Cistian A. Rojas Barahona, Dr. Ps.}

Profesor AsociadolAssociate Profiesso

Facultad de Educcción

Pontificia Universidad Catilica de Chite

Av. Vicuña Mackenna 4860

Macul Santiago, Chile

Fone (562) 2)2354 53

wano. (56 2) 2354 53 .educacionucc. 


\section{APÉNDICE 15: Permiso de Relationship Contingent Self - Esteem Scale}

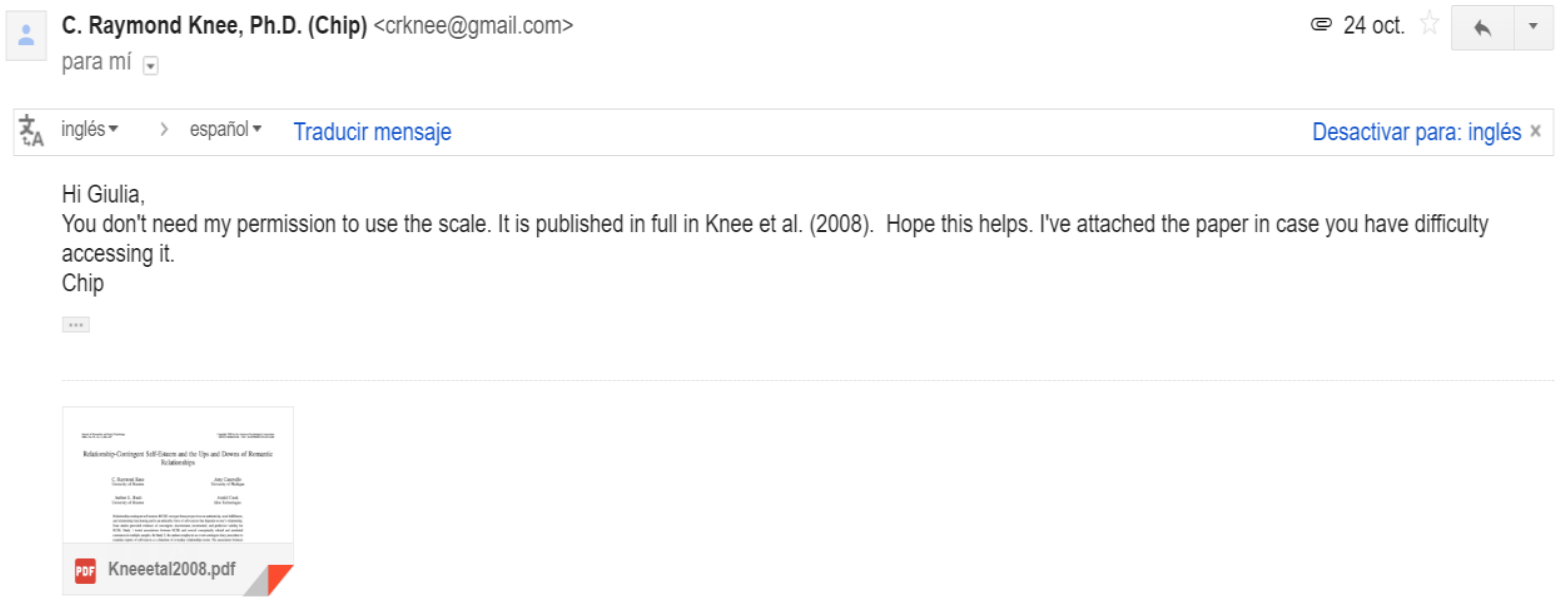




\section{APÉNDICE 16: Consentimiento Informado}

La presente investigación es conducida por Giulia Camaiora Chiappe, Bachiller de Psicología de la Universidad de Lima. El objetivo de este estudio es poder analizar cómo es que se sienten las mujeres en relación a sí mismas y a su relación de pareja. Para ello, se le pedirá que responda 3 cuestionarios, con una duración aproximada de 30 minutos. Las respuestas a los cuestionarios serán codificadas usando un número de identificación y por lo tanto, serán anónimas.

La participación en este estudio es completamente voluntaria. La información que se recoja será confidencial y no se usará para ningún otro propósito fuera de los de esta investigación.

Si tiene alguna duda sobre este proyecto, puede hacer preguntas en cualquier momento durante la participación. Igualmente, puede retirarse del mismo sin que eso la perjudique de ninguna forma. Si alguna de las preguntas le parece incómoda, tiene el derecho de hacérselo saber al investigador o de no responderla. Ante cualquier consulta puede contactar a Giulia Camaiora Chiappe al correo electrónico 20110222@aloe.ulima.edu.pe.

Desde ya le agradezco su participación.

Acepto participar voluntariamente en esta investigación, conducida por Giulia Camaiora Chiappe. He sido informada de que la meta de este estudio es evaluar cómo se sienten las mujeres en relación a sí mismas y a sus parejas.

Me han indicado también que tendré que responder a 3 cuestionarios, lo cual me tomará aproximadamente 30 minutos.

Reconozco que la información que yo provea en el curso de esta investigación es estrictamente confidencial y no será usada para ningún otro propósito fuera de los de este estudio sin mi consentimiento. He sido informada de que puedo hacer preguntas sobre el proyecto en cualquier momento y que puedo retirarme del mismo cuando así lo decida, sin que esto acarree perjuicio alguno para mí.

Entiendo que una copia de esta ficha de consentimiento me será entregada y que puedo pedir información sobre los resultados de este estudio cuando éste haya concluido. Para esto, puedo contactar al investigador al correo electrónico antes mencionado.

Nombre del participante

Firma del participante

Fecha 


\section{APÉNDICE 17: Cronograma}

\begin{tabular}{|c|c|c|c|c|c|c|c|c|c|c|c|c|c|c|c|c|c|c|c|c|c|c|c|}
\hline & Ener & & & Febre & & & & Marzo & & & Abril & & & & layo & & & Junio & & & Julio & & \\
\hline Actividades & $\mathrm{S} 1$ & S2 & \begin{tabular}{l|l} 
S3 & S4 \\
\end{tabular} & \begin{tabular}{l|l|}
4 & $\mathrm{~S} 1$ \\
\end{tabular} & $\mathrm{~s} 2$ & \begin{tabular}{l|l}
$\mathrm{S} 3$ & $\mathrm{~S}$ \\
\end{tabular} & $84 \mathrm{~s}$ & \begin{tabular}{l|l} 
S1 & $\mathrm{s}$ \\
\end{tabular} & S2 $2 \mathrm{~s}$ & \begin{tabular}{l|l|}
$\mathrm{S} 3$ & $\mathrm{~S} 4$ \\
\end{tabular} & S1 & $\mathrm{s} 2 \mathrm{~s}$ & \begin{tabular}{l|l}
$\mathrm{S} 3$ & $\mathrm{~S}$ \\
\end{tabular} & \begin{tabular}{l|l}
$\mathrm{S} 4$ & $\mathrm{~S} 1$ \\
\end{tabular} & \begin{tabular}{|l|l|}
$\mathrm{S} 1$ & $\mathrm{~S} 2$ \\
\end{tabular} & S3 & $\mathrm{S} 4$ & S1 & \begin{tabular}{l|l}
$\mathrm{S} 2$ & $\mathrm{~S}$ \\
\end{tabular} & \begin{tabular}{|l|l|}
$\mathrm{S} 3$ & $\mathrm{~S} 4$ \\
\end{tabular} & S1 & $\mathrm{S} 2 \mathrm{~s}$ & \begin{tabular}{l|l}
$\mathrm{S} 3$ & $\mathrm{~S}$ \\
\end{tabular} \\
\hline $\begin{array}{c}\text { 1. Revisión del } \\
\text { planteamiento del } \\
\text { problema y traducción de } \\
\text { la prueba } \\
\end{array}$ & & & & & & & & & & & & & & & & & & & & & & & \\
\hline $\begin{array}{l}\text { 2. Modificación del marco } \\
\text { teórico y bibliografía }\end{array}$ & & & & & & & & & & & & & & & & & & & & & & & \\
\hline $\begin{array}{l}\text { 3. Realizar permisos para } \\
\text { aplicar las pruebas }\end{array}$ & & & & & & & & & & & & & & & & & & & & & & & \\
\hline 4. Preparación del material & & & & & & & & & & & & & & & & & & & & & & & \\
\hline $\begin{array}{c}\text { 5. Aplicación de las } \\
\text { pruebas }\end{array}$ & & & & & & & & & & & & & & & & & & & & & & & \\
\hline $\begin{array}{l}\text { 6. Digitación de los datos } \\
\text { recogidos } \\
\end{array}$ & & & & & & & & & & & & & & & & & & & & & & & \\
\hline $\begin{array}{c}\text { 7. Análisis estadísticos de } \\
\text { los resultados }\end{array}$ & & & & & & & & & & & & & & & & & & & & & & & \\
\hline 8. Redacción resultados & & & & & & & & & & & & & & & & & & & & & & & \\
\hline 9. Redacción discusión & & & & & & & & & & & & & & & & & & & & & & & \\
\hline $\begin{array}{l}\text { 10. Redacción de las } \\
\text { conclusiones }\end{array}$ & & & & & & & & & & & & & & & & & & & & & & & \\
\hline $\begin{array}{l}\text { 11. Redacción de las } \\
\text { recomendaciones }\end{array}$ & & & & & & & & & & & & & & & & & & & & & & & \\
\hline 12. Revisión final & & & & & & & & & & & & & & & & & & & & & & & \\
\hline
\end{tabular}




\section{APÉNDICE 18: Presupuesto}

\begin{tabular}{|c|c|c|c|c|}
\hline & Descripción & Unidades & Precio unitario & Precio total \\
\hline \multirow{4}{*}{$\begin{array}{c}\text { Fotocopias } \\
\text { (Instrumentos) }\end{array}$} & $\begin{array}{c}\text { Inventario de } \\
\text { Dependencia } \\
\text { Emocional } \\
\end{array}$ & 200 & 0.10 céntimos & 40 soles \\
\hline & $\begin{array}{c}\text { Inventario de } \\
\text { Autoestima de } \\
\text { Rosenberg }\end{array}$ & 200 & 0.10 céntimos & 20 soles \\
\hline & $\begin{array}{c}\text { Escala de } \\
\text { Autoestima } \\
\text { Contingente a una } \\
\text { Relación de Pareja }\end{array}$ & 200 & 0.10 céntimos & 20 soles \\
\hline & Ficha Demográfica & 200 & 0.10 céntimos & 20 soles \\
\hline Útiles & Lapiceros & 50 & $1 \mathrm{sol}$ & 50 soles \\
\hline Instrumentos & $\begin{array}{l}\text { Inventario de } \\
\text { Dependencia } \\
\text { Emocional }\end{array}$ & 1 & 175 soles & 175 soles \\
\hline 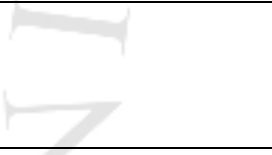 & $\begin{array}{c}\text { Cuestionario de } \\
\text { Autoestima de } \\
\text { Rosenberg }\end{array}$ & 1 & 0 soles & 0 soles \\
\hline Traducciones & $\begin{array}{c}\text { Escala de } \\
\text { Autoestima } \\
\text { Contingenta a una } \\
\text { relación de pareja }\end{array}$ & 1 & 350 soles & 350 soles \\
\hline Movilidad & $\begin{array}{c}\text { Tanque de gasolina } \\
\text { para cuestiones } \\
\text { determinadas para } \\
\text { el proyecto }\end{array}$ & 1 & 150 soles & 150 soles \\
\hline & Presupuesto & tal & & 805 soles \\
\hline
\end{tabular}

